\title{
Who wants to learn harder? The relationship between conservatism and liberalism, desirable difficulties, and academic learning
}

\author{
Antonia Mariss $^{1}$ (D) Kristin Wenzel ${ }^{1}$ (D) Chawwah Grünberg $^{1}$. \\ Marc-André Reinhard ${ }^{1}$
}

Received: 11 September 2020 / Accepted: 20 November 2021 / Published online: 4 January 2022

(c) The Author(s) 2022

\begin{abstract}
Previous work has shown that challenging learning strategies like desirable difficulties improve long-term learning. Nonetheless, because they might be regarded as strict and demanding learning strategies, they should not be perceived as positive by everyone. They should, however, fit conservative political attitudes since those are, among others, positively correlated with individuals' need for order and structure as well as with challenging learning environments. Hence, we hypothesized conservative political attitudes to be correlated with more positive attitudes towards desirable difficulties, towards the use of desirable difficulties at school, towards the preferred difficulty of the learning process, and towards deeper learning strategies. We conducted three online studies assessing US American students' political attitudes and their attitudes towards such difficult and challenging learning strategies: Study 1 found correlations among more conservative political attitudes and more positive attitudes towards difficult and challenging learning strategies, whereas Study 2 found no significant linkages among these variables. Study 3 then showed that a more conservative political attitude and favorable ratings of Republican politicians, but also more favorable ratings of Democratic politicians were linked to more positive attitudes towards our dependent variables. Self-reported interest in and importance of politics were also positively correlated with positive attitudes towards difficult learning. Our results indicate that students' political attitudes are generally linked to positive attitudes towards difficult and challenging learning strategies and are therefore important individual characteristics regarding applications and perceptions of these learning strategies. Future work focusing on these relationships, on causal effects, and on further related variables is valuable.
\end{abstract}

Keywords Desirable difficulties · Learning · Education · Political attitudes · Conservatism $\cdot$ Liberalism

Antonia Mariss and Kristin Wenzel shared first-authorship.

Extended author information available on the last page of the article 


\section{Introduction}

Due to the importance of life-long learning, successful education, and knowledge acquisition, much research has focused on ways to improve learning outcomes and academic success. For instance, previous work has often shown that especially challenging and intentionally hindered learning strategies like desirable difficulties ( $\mathrm{R}$. A. Bjork, 1994) improve later retention and long-term learning. However, because these desirable difficulties at first increase the difficulty of the learning process and are only beneficial later on, they might not be directly perceived as useful or positive by every learner. It is therefore of great relevance to explore personality variables and individual characteristics that might influence learners' perceptions, attitudes, and applications of such difficult and challenging learning strategies (see e.g., McDaniel \& Butler, 2011; Weissgerber et al., 2016). One of these variables could, among others, be learners' political orientation: In general, political attitude has been the focus of previous research, linking it to various variables like fear of threat or of loss, self-esteem, and cognitive abilities (e.g., Adorno et al., 1950; Hinze et al., 1997; Jost et al., 2003a, 2003b). In addition, the linkage between political attitudes and education-related variables can be regarded as being of great relevance. For instance, Thomas (2016) described a symbiotic relationship between politics and education. He suggested that politicians support education more in the region they come from and that students rather join the armed forces after they have been taught patriotism at school. Previous work also showed that parents' political attitude influenced their attitudes about sex education at school (Bleakley et al., 2010). Most important, according to Ajzen (1991), an individual's attitude towards a specific behavior is related to actual performance of that behavior. Thus, individuals' attitudes towards education might be related to their actual behavior concerning education-related issues like the usage of different learning strategies or persistence while learning. Given the importance of children and students' education for our future, it is crucial to get to a better understanding of linkages among education and politics. In a first step, it helps to take a closer look at individuals' self-reported attitudes and to observe relationships among their political attitudes and their attitudes towards education: For this reason, the present work focused on correlations of students' attitudes towards intentionally hindered learning strategies like desirable difficulties (e.g., R. A. Bjork, 1994; Bjork \& Bjork, 2011) and their political attitudes (ranging from liberal to conservative)-thus, investigating the above-mentioned linkages among politics, learning, and education.

\subsection{Political attitudes, politics, and education}

As mentioned above, it is assumed that a country's politics and its education affect each other (e.g., Thomas, 2016; see also Busemeyer \& Trampusch, 2011, for a review article concerning political science and the study of education). Besides, different political parties that are present in a country's political system have different opinions on how education should be managed or supported and on how education 
should look like. For instance, research focusing on four countries in Western Europe (England, the Netherlands, Norway, and one German Bundesland) showed that different political parties have varying preferences regarding higher education policy, among others concerning the re-distributive characteristics and the public governance of higher education (Jungblut, 2016). More specifically, Jungblut (2016) reported that more conservative or Christian democratic parties prefer restrictive, de-centrally controlled higher education systems, whereas more liberal parties prefer expensive, de-centrally controlled higher education. In contrast, more green, antiestablishment, or social democratic parties were found to prefer expansive, centrally controlled higher education systems. Fittingly, Wiborg (2015) showed and argued that differences in Free School Policies (and thus differences concerning the amount of state-funded but privately run schools) between England and Sweden can best be explained by differences in their political systems (e.g., concerning differences due to the two-party system in England and the multiparty system in Sweden). In the United States, differences in attitudes towards educational variables can be observed between the Democratic and the Republican party: More specifically, liberals are associated with the idea that public schools are part of the ideal school system and should be provided with more support from the government ("Conservative vs. Liberal Beliefs", 2010). The Democratic party also announced in their platform that they aim for high-quality education to be accessible for everyone from an early age onwards, for generally including everyone, and for promoting innovation (Democratic Platform Committee, 2016). Conservatives, on the other hand, are associated with supporting the idea of vouchers as a form of student funding to create competition between students and to encourage schools to improve their performance ("Conservative vs. Liberal Beliefs", 2010). Historically, Republicans have been a party of order which valorized work and thought of humans as being responsible for reforming themselves and society (Gerring, 2001). Besides, the Republican party stated in their platform as of 2016 that "the greatest asset of the American economy is the hard-working American" (Republican National Committee, 2016, p.40). They also spoke of "higher expectations for all students" (p.40) and instead of testing excessively or "teaching to the test" (p.40) they stated that they prefer strong assessments to help teachers adapt to students' needs. To help every student to reach their own potential and "to attract the best talent to the classroom", the Republican party reportedly relies on a "merit-based approach" (p.40). In total, these statements from the Republican party create an image of hard work and performance. Consequently, although the reported contrasts between Democrats and Republicans are only exemplary, they suggest that the two parties' approaches towards education strongly differ from each other.

Given the presented findings, it can be assumed that politics and education interact, and that the political orientation of the governing party can have an influence on the educational system and on the practical implementations of education (e.g., Thomas, 2016). Notably, a linkage between politics and education is not only important regarding the politicians in charge but also regarding individuals that hold favorable views of such politicians, agree with their work, or share the same political attitudes as the political party or the respective politicians. For instance, previous work conducted in Switzerland showed that individuals' political attitudes and their 
affiliations to partisan ideologies were important concerning their attitudes towards investment in and the financing of higher education (Busemeyer et al., 2011): More specifically, proponents of the left (contrary to proponents of the right) preferred higher investments both from the state as well as from private sectors and were more opposed to the notion that students should pay for attending universities themselves through individual tuition fees. In line with this, Garritzmann (2015) showed that among 22 countries-including among others Japan, New Zealand, Australia, Canada, Spain, and Slovenia-individuals' political attitudes were linked to their attitudes towards supporting students from low-income families: Those individuals that preferred redistribution and higher public education spending (like more left-wingoriented individuals in comparison to more right-wing-oriented individuals) were more likely to have positive attitudes towards supporting students financially and towards subsidies. Hence, it seems relevant to focus on the educational experiences and preferences of students themselves: For instance, specific learning strategies like desirable difficulties, as well as students' acceptance of those strategies and their applications in school or university contexts, are educational variables that students are directly affected by and that should thus be considered more thoroughly.

\subsection{Desirable difficulties as intentionally hindered learning strategies}

In the context of education and learning, past researchers often described beneficial learning strategies as desirable difficulties (e.g., R. A. Bjork, 1994). These include learning strategies that are intentionally hindered, more difficult, and effortfulthus, that seem to be more complicated and exhausting at first-but increase later long-term learning results like retention, recall, and transfer (e.g., R. A. Bjork, 1994; Bjork \& Bjork, 2011; R. A. Bjork \& Kroll, 2015; Dobson \& Linderholm, 2015; Roediger \& Karpicke, 2006). This contradicts human intuition: Students normally regard easy and fluent learning strategies as more effective for their learning process and most students prefer more simple strategies like repeated reading-and such misconceptions do not only concern undergraduates but also teachers-to-be (e.g., E. L. Bjork et al., 2015; Book et al., 1983; Karpicke et al., 2009; Koriat \& Ma'ayan, 2005). However, despite students' preference of easy-going learning strategies, these often lead to reduced learning effects in the end (e.g., Bjork \& Bjork, 2019; Diemand-Yauman et al., 2010). In contrast, desirable difficulties elicit beneficial long-term effects on learning especially because they are more difficult and demanding, require more effort, more (cognitive) resources, and deeper levels of information processing (R. A. Bjork, 1994; Bjork \& Bjork, 1992; Craik \& Tulving, 1975; Pyc \& Rawson, 2009; Roediger \& Karpicke, 2006; Tyler et al., 1979). By overcoming such challenges, deeper and more elaborated encoding and retrieval processes are stimulated, which, in turn, lead to improved long-term learning outcomes (e.g., Bjork \& Bjork, 2011; R. A. Bjork, 1994; Craik \& Tulving, 1975; Yan et al., 2016, as cited in Weissgerber \& Reinhard, 2017). In general, different types of such hindered and cognitively challenging learning strategies exist: For instance, interleaving (shuffling different topics instead of blocking practice on separate topics), disfluency (using harder-to-read fonts), generation (generating materials and 
solutions oneself instead of passive consumption), and testing (taking learning tests or quizzes as retrieval practice; e.g., Bertsch et al., 2007; Diemand-Yauman et al., 2010; Roediger \& Karpicke, 2006; Weissgerber et al., 2018). We argue that it is important to investigate how students perceive these difficult but beneficial learning strategies and if teachers or lecturers would apply them in their educational courses. Accordingly, it should also be investigated if students themselves would use desirable difficulties and which individual characteristics might influence their attitudes towards these learning strategies.

\subsection{The present research}

In line with the argumentation presented above, we supposed that political attitudes and attitudes towards difficult and challenging learning strategies like desirable difficulties are correlated. Firstly focusing on the United States, desirable difficulties as difficult and challenging learning strategies should fit Republican attitudes, Republican preferences for a hard-working mankind, and generally more conservative world views. Hence, we hypothesized a conservative attitude to be positively correlated with positive attitudes towards desirable difficulties (Hypothesis 1), towards the use of desirable difficulties at school (Hypothesis 2), towards the preferred difficulty of the learning process (Hypothesis 3), and towards deeper learning styles (Hypothesis 4).

Despite the relevance of the assumed linkages, we were not able to find previous research already linking these variables, neither in the United States nor elsewhere. Hence, our study focused on empirically well-established desirable difficulties to test correlations among political attitudes and attitudes regarding such difficult and challenging learning strategies. We thereby concentrated on students since their political attitudes might be more mature compared to pupils' political attitudes, while their interest in learning and school should be bigger than that of non-student grown-ups. In addition, students are the ones directly experiencing the outcomes of political decisions and changes concerning education and are likely to shape its development in the future. Therefore, we see a great relevance of testing the link between politics and education using students as participants.

Moreover, despite the wide-ranging relevance of the hereby raised research issues across multiple countries, our work focused solely on the United States and on political attitudes ranging from more conservative to more liberal. Because the present research was conducted as a first approach, we deemed it to be more plausible to firstly focus on a two-party political system as it exists in the United States compared to a multiparty system (often including coalitions) as it exists in many European countries (see e.g., Hallermann \& Kaim, 2003, concerning differences and similarities of these political systems). In contrast to the political system in the United States, the greater variation of political parties in a multiparty system might make valid data collections more difficult and more complex because it might be questionable whether a one-dimensional continuum could reliably assess political attitudes or if this would require a more facetted assessment (see e.g., Garritzmann \& Seng, 2016; Krieger et al., 2019). Accordingly, we decided to collect our data 
from US American participants. This way, we wanted to make sure that the recruited participants actually held more conservative or more liberal political attitudes, knew the political system in the United States, and knew the most important American politicians of the two political parties.

\section{Study 1}

\subsection{Method}

\subsubsection{Participants}

Participants were recruited via the frequently used platform Amazon Mechanical Turk (MTurk), which enabled us to collect data from American students. MTurk has been shown to provide representative samples of the United States population (Minton et al., 2013) as well as samples that are more diverse and more attentive than typical American college samples (Buhrmester et al., 2011; Hauser \& Schwarz, 2016). Of the 500 recruited participants, only 491 participants finished the survey and passed an included attention test. We then excluded further 79 participants because they stated that they did not know (at least) one of six politicians mentioned during our study. Hence, the final sample consisted of $N=412$ participants $\left(M_{\text {age }}=27.40, S D_{\text {age }}=7.44\right.$, range: $18-66 ; 179$ females, 232 males, 1 participant chose not to specify). Of these, all were college/university students, 297 reported that they had at least one graduate parent, and 395 were currently living in the United States. Participants were remunerated with US\$ 0.60 .

\subsubsection{Procedure and measures}

Before starting the survey, all participants had to read and agree to a declaration of consent confirming that they would answer the questions voluntarily and were at least 18 years old. They were also explicitly informed that all their data would be treated confidentially and that they could withdraw from the study at any given time, without explanation, by simply closing the internet browser. Afterwards, participants were asked about their demographic information such as age, gender, native language, occupational status, highest educational attainment of their parents, and whether their siblings had graduated from college/university or not. Next, participants' political attitudes and their attitudes towards different difficult and challenging learning strategies were assessed.

2.1.2.1 Political attitudes Participants rated the favorableness of six politicians on a 5-point Likert-like scale of 1 (very unfavorable) to 5 (very favorable) with an additional option 6 (never heard about). These ratings were conducted to serve as a more indirect assessment of political attitudes (see Pfattheicher \& Schindler, 2016). The politicians rated were Bernie Sanders, Elizabeth Warren, and Hillary Clinton as representatives for the Democratic party and Donald Trump, Mike Pence, and Paul Ryan as representatives for the Republican party. These six politi- 
cians were chosen because according to the Harris Poll (2017) they were the three most known Democrats and the three most known Republicans when we conducted our survey in December 2017. To test if these ratings of politicians really assessed participants' political orientation, we ran a factorial analysis, which yielded two factors: Factor 1 consisted of the favorableness ratings of the three Republican politicians Donald Trump, Mike Pence, and Paul Ryan (average score of the three items: ratings of Republicans; $\alpha=0.85$ ). Factor 2 consisted of the favorableness ratings of the three Democratic politicians Bernie Sanders, Elizabeth Warren, and Hillary Clinton (average score of the three items: ratings of Democrats; $\alpha=0.71$ ). A detailed description of the factor analysis and the respective table depicting the items' loadings are available in Appendix A. The following analyses will use the ratings of Democrats and the ratings of Republicans as variables instead of each rating of the six politicians as a separate variable as the factor analysis indicated that the two resulting variables can indeed be regarded as more indirect measurements of participants' political attitudes.

In addition, participants were asked to self-report their political attitude on a 7-point Likert-like scale from 1 (liberal) to 7 (conservative). This variable served as another, more direct, assessment of participants' political attitude.

2.1.2.2 Difficult and challenging learning strategies To get a full picture of participants' attitudes towards more effortful learning, we assessed four different dependent variables. Throughout this work, we will use the term difficult and challenging learning strategies as an umbrella term for these dependent variables. First, to measure participants' attitude towards desirable difficulties, we applied a scale created by Weissgerber et al. (2018). The scale included 15 items $(\alpha=0.93)$ and assessed five different types of desirable difficulties: self-generation of materials, self-generation of predictions, self-testing, interleaving/spacing, and generation/testing by practicing. For each desirable difficulty one affective item, one cognitive item, and one behavioral item were applied. For instance, the affective item for self-generation of predictions read "I enjoy predicting solutions", the cognitive item read "I think I remember things better if I try to deduce the solution myself", and the behavioral item read "Prior looking up a solution, I generate the answers myself". Participants answered the items on a 7-point Likert-like scale from 1 (totally disagree) to 7 (totally agree). Additionally, we included one attention-test-question instructing participants to select 7 (totally agree) to see whether they read the items carefully. Participants who failed this attention test were excluded.

Following the five types of desirable difficulties included in the measurement described above, we developed five items asking about participants' attitude towards the use of desirable difficulties at school $(\alpha=0.81)$. Participants answered these items on a 7-point Likert-like scale from 1 (totally disagree) to 7 (totally agree). For instance, one item read "In school students should acquire knowledge themselves" (see Appendix B for all items).

Next, participants' attitude towards the preferred difficulty of the learning process $(\alpha=0.72$; see Appendix B) was assessed: We developed three items reading "Learning at school should be..." that participants answered on a 7-point Likert-like scale 
from 1 (easy/not challenging at all/not exhausting at all) to 7 (hard/extremely challenging/extremely exhausting).

To measure participants' attitude towards deeper learning styles, we applied 25 items of Vermunt's (1994) Inventory of Learning Styles and used their conducted mean score for later analyses $(\alpha=0.90)$. We chose the items that focused on deeper and more challenging learning styles, which should therefore be related to desirable difficulties and their theoretical foundation. More specifically, we chose six items concerning the process of relating and structuring of information, four items concerning critical processing of information, and five items concerning memorizing and rehearsing of information. Participants answered these items on a 5-point Likert-like scale from 1 (I seldom or never do this) to 5 (I (almost) always do this). Furthermore, we chose five items concerning construction of knowledge and five items concerning the intake of knowledge, which were answered on a 5-point Likert-like scale from 1 (completely disagree) to 5 (completely agree).

\subsection{Results}

Table 1 shows descriptive statistics and correlations among the variables measuring political attitudes and attitudes towards difficult and challenging learning strategies. Notably, the ratings of Democrats $(M=3.37, S D=1.10)$ were regarded as significantly more favorable than the ratings of Republicans $(M=2.54, S D=1.31)$, $t(411)=8.82, p<0.001$. The average of the self-reported political attitude $(M=3.57$, $S D=1.80)$ significantly differed from the mean of the used scale $(M=4.00)$, $t(411)=-4.90, p<0.001$, also indicating that participants in our sample were slightly more liberal than conservative.

The correlations reported in Table 1 further served as first evidence for our hypotheses: Participants' attitude towards desirable difficulties was positively related to their self-reported political attitude $(r=0.15, p=0.003)$ and to the ratings of Republicans $(r=0.15, p=0.003)$. This indicated that a more conservative political attitude was associated with a more positive attitude towards desirable difficulties. The correlation between participants' attitude towards desirable difficulties and the ratings of Democrats was not significant $(r=0.07, p=0.191)$. Participants' attitude towards the use of desirable difficulties at school was also positively related to political attitude $(r=0.13, p=0.010)$ and to the ratings of Republicans $(r=0.13$, $p=0.006)$, but not to the ratings of Democrats $(r=0.03, p=0.609)$. Political attitude was also positively related to the attitude towards the preferred difficulty of the learning process $(r=0.10, p=0.038)$, while the correlations between attitude towards the difficulty of the learning process and the ratings of Republicans $(r=0.08, p=0.108)$ and the ratings of Democrats $(r=-0.01, p=0.896)$ were not significant. Notably, participants' attitude towards deeper learning styles was not significantly related to self-reported political attitude $(r=0.07, p=0.183$ ), but to the ratings of Republicans $(r=0.12, p=0.019)$, and to the ratings of Democrats $(r=0.15, p=0.003)$. Summarizing, we found support for all hypotheses, indicating that more conservative political attitudes were related to more positive attitudes towards difficult and challenging learning strategies. 


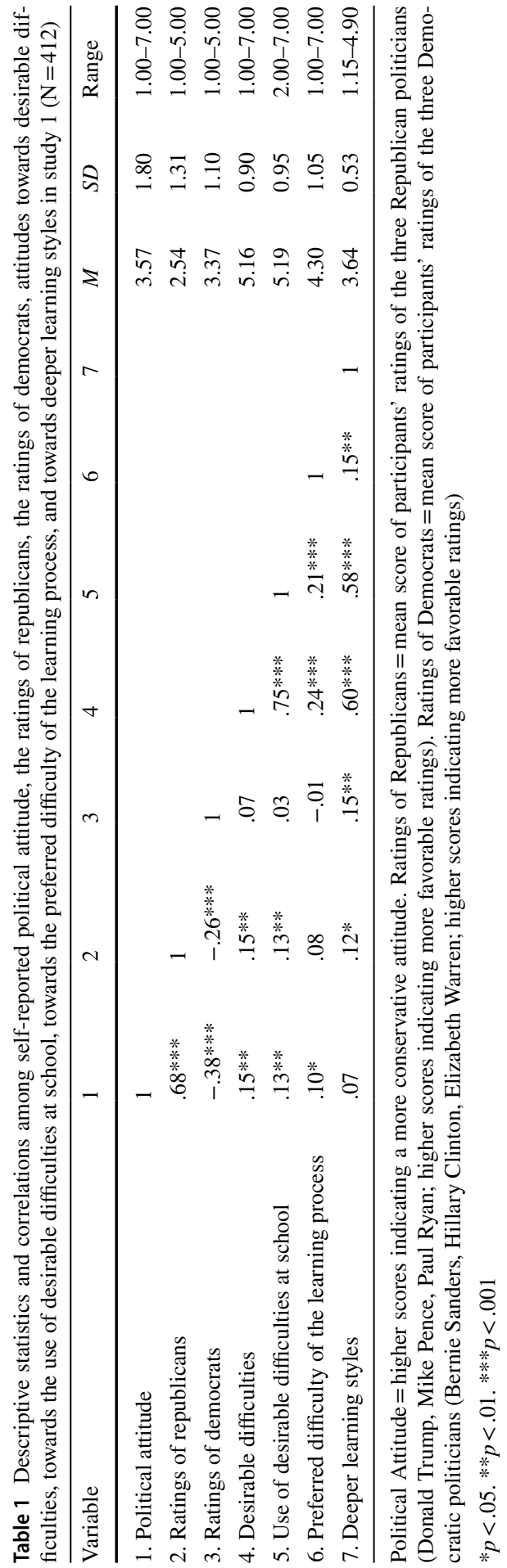


We additionally conducted hierarchical regression analyses on our four dependent variables, to respectively test if the effects of self-reported political attitude would change when controlling for the ratings of Republicans and for the ratings of Democrats. Consequently, to test Hypothesis 1 in more detail, we conducted hierarchical regression analyses predicting participants' attitude towards desirable difficulties: In a first model, we used the self-reported political attitude as a predictor. $R$ for this regression was significantly different from zero, $F(1410)=9.14, p=0.003$, and could explain $2.20 \%$ (1.90\% adjusted) of the variability. Self-reported political attitude was a significant predictor, $t(410)=3.02, B=0.13, S E=0.04, \beta=0.148, p=0.003$. In a second model (see Table 2), the ratings of Republicans and the ratings of Democrats were added as predictors. $R$ for this regression was significantly different from zero, $F(3408)=6.09, p<0.001$, and could explain $4.30 \%$ ( $3.60 \%$ adjusted) of the variability. This second model explained significantly more variance than the first model, $F_{\text {change }}=4.49, p=0.012$. Self-reported political attitude remained a significant predictor, $t(408)=2.10, p=0.036$. The ratings of Republicans, however, had no significant effect, $t(408)=1.27, p=0.206$, while the ratings of Democrats had a significant effect in the equation, $t(408)=2.71, p=0.007$.

To test Hypothesis 2 in more detail, we then conducted hierarchical regression analyses predicting participants' attitude towards the use of desirable difficulties at school: In a first model, we used the self-reported political attitude as a predictor. $R$ for this regression was significantly different from zero, $F(1410)=6.76, p=0.010$, and could explain $1.60 \%$ ( $1.40 \%$ adjusted) of the variability. Self-reported political attitude was a significant predictor, $t(410)=2.60, B=0.12, S E=0.05, \beta=0.127$, $p=0.010$. In a second model (see Table 2), the ratings of Republicans and the ratings of Democrats were added as predictors. $R$ for this regression was significantly different from zero, $F(3408)=3.76, p=0.011$, and could explain $2.70 \%(2.00 \%$ adjusted) of the variability. This second model did not significantly explain more variance than the first model, $F_{\text {change }}=2.23, p=0.108$. None of the predictors was significant: neither self-reported political attitude, $t(408)=1.45, p=0.149$, nor the ratings of Republicans, $t(408)=1.33, p=0.186$, nor the ratings of Democrats, $t(408)=1.64, p=0.101$.

To test Hypothesis 3 in more detail, we conducted hierarchical regression analyses predicting participants' attitude towards their preferred difficulty of the learning process. In a first model, we used the self-reported political attitude as a predictor. $R$ for this regression was significantly different from zero, $F(1410)=4.31$, $p=0.038$, and explained $1.00 \%(0.80 \%$ adjusted $)$ of the variability. Self-reported political attitude was a significant predictor, $t(410)=2.08, B=0.11, S E=0.05$, $\beta=0.102, p=0.038$. In a second model (see Table 2), the ratings of Republicans and the ratings of Democrats were added as predictors. $R$ for this regression was not significantly different from zero, $F(3408)=1.63, p=0.182$, and explained $1.20 \%$ $(0.50 \%$ adjusted $)$ of the variability. This second model did not explain more variance than the first model, $F_{\text {change }}=0.30, p=0.743$. None of the predictors was significant: neither political attitude, $t(408)=1.48, p=0.139$, nor the ratings of Republicans, $t(408)=0.27, p=0.784$, nor the ratings of Democrats, $t(408)=0.72, p=0.472$.

To test Hypothesis 4 in more detail, we then conducted hierarchical regression analyses predicting participants' attitude towards deeper learning styles. In a first 


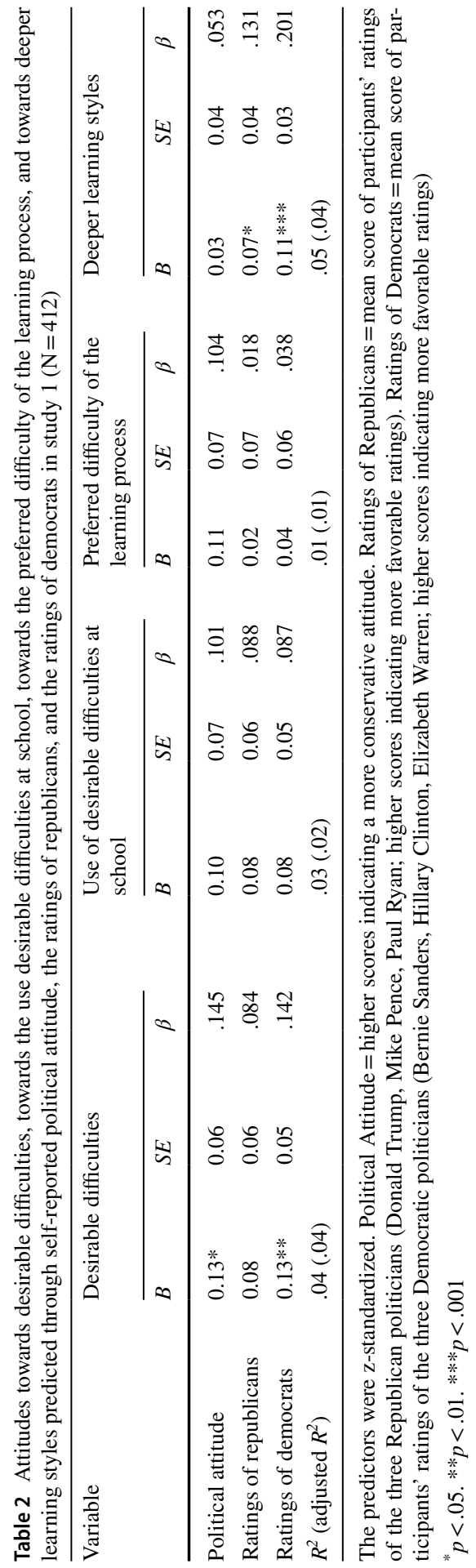


model, we used the self-reported political attitude as a predictor. $R$ for this regression was not significantly different from zero, $F(1410)=1.78, p=0.183$, and explained $0.40 \%(0.20 \%$ adjusted $)$ of the variability. Self-reported political attitude was not a significant predictor, $t(410)=1.33 B=0.04, S E=0.03, \beta=0.066, p=0.183$. In a second model (see Table 2), the ratings of Republicans and the ratings of Democrats were added as predictors. $R$ for this regression was significantly different from zero, $F(3408)=6.86, p<0.001$, and could explain $4.80 \%$ ( $4.10 \%$ adjusted) of the variability. This second model could significantly explain more variance than the first model, $F_{\text {change }}=9.36, p<0.001$. Self-reported political attitude was not significant, $t(408)=0.78, p=0.438$. The ratings of Republicans, $t(408)=1.99, p=0.047$, and ratings of Democrats, $t(408)=3.83, p<0.001$, were significant predictors. None of the presented results differed when controlling for participants' age or gender.

\subsection{Discussion}

All our hypotheses were supported by the correlational analyses depicted in Table 1: As expected, participants' self-reported political attitude was positively correlated with their attitudes towards desirable difficulties, towards the use of desirable difficulties at school, and towards the preferred difficulty of the learning process. Participants' attitude towards deeper learning styles was positively correlated with the ratings of Republicans, which represent a more indirect assessment of conservative political attitude. Thus, in sum, more conservative political attitudes were linked to more positive attitudes towards difficult and challenging learning strategies. These findings are in line with the assumption that desirable difficulties signify an elaborate and challenging way of learning and should therefore fit the worldview of the Republican Party including an image of hard-working mankind.

These results were additionally supported by the conducted hierarchical regression analyses: Participants' attitudes towards the use of desirable difficulties at school and towards the preferred difficulty of the learning process could respectively be best explained by the first regression model solely containing self- reported political attitude as a positive predictor. This again supported Hypotheses 2 and 3 claiming a more conservative political attitude to be linked to more positive attitudes towards difficult learning. Participants' attitudes towards desirable difficulties and towards deeper learning styles could respectively be best explained by the second regression model containing all three measures of political attitudes. Concerning the attitude towards desirable difficulties, both self-reported political attitude and the ratings of Democrats were significant and positive predictors. Concerning the attitude towards deeper learning styles, the ratings of Republicans and the ratings of Democrats were significant and positive predictors. These findings partly supported Hypotheses 1 and 4 because they again yielded positive linkages with more conservative political attitudes but also revealed unexpected positive effects of the ratings of Democrats as an indicator of more liberal political attitudes.

It is striking that when controlling for self-reported political attitude and the ratings of Republicans, the ratings of Democrats became a significant predictor for the attitude towards desirable difficulties even though there had been no zero-order 
correlation between these two variables (see Table 1). Thus, although self-reported political attitude and more favorable ratings of Democrats represent different and partly opposite political attitudes, both variables were positively correlated with a more positive attitude towards desirable difficulties. This also applies to the regression analysis predicting the attitude towards deeper learning styles, in which both the ratings of Democrats and the ratings of Republicans were positive and significant predictors despite representing different and partly opposite political attitudes. Thus, the question arises why the results change once the ratings of the Republicans and Democrats were added as predictors alongside the self-reported political attitude. It is especially interesting because the zero-order correlations among these three predictors themselves show interrelationships which were to be expected (see Table 1): The ratings of Democrats were negatively correlated with the self-reported political attitude and with the ratings of Republicans. These were, in turn, positively correlated with each other. Still, the strength of the respective correlations indicated that the self-reported political attitude was not identical to the more indirect assessments of political attitudes via the favorable ratings of the politicians. The conducted factor analysis (see Appendix A) supported this assumption, insofar as that the two underlying factors indicating the political party of the presented politicians were not able to completely explain all variability among these six items. Thus, we argue that when all three predictors were simultaneously applied and controlled for in regression analyses, the self-reported political attitude should primarily consist of participants' political orientation, whereas the ratings of Republicans and Democrats contain further aspects additional to and beyond the political attitude of the politicians. We presume that such aspects could be feelings of sympathy towards the politicians, evaluations of the politicians' personalities, individuals' general interest in politics, or participants' perceived importance of politics. Future inquiries regarding individuals' reasons for their ratings and views of politicians thus seem to be extremely valuable. Hence, future work replicating our findings should include the three assessments of political attitudes but should also add further variables that might be connected to the ratings of politicians as well as to individuals' political attitudes. Based on these stimulating considerations, we decided to conduct a second study.

\section{Study 2}

Study 2 was conducted to try to replicate the findings of Study 1, which indicated linkages among political attitudes and attitudes towards difficult and challenging learning strategies. To increase the validity and reliability of our assessment, we used a different scale - instead of one single item-for measuring participants' selfreported political attitude. Additionally, we asked participants about their reasons regarding the ratings of the politicians to inquire how they reached these decisions and which other aspects of the politicians might have influenced participants' ratings apart from their political orientations. In line with this, we also added assessments of participants' political interest and their perceptions of the importance of politics as further variables possibly linked to political attitudes. We predicted the same four 
hypotheses as in Study 1, assuming a more conservative political attitude to be positively correlated with more positive attitudes towards desirable difficulties (Hypothesis 1), towards the use of desirable difficulties at school (Hypothesis 2), towards the preferred difficulty of the learning process (Hypothesis 3), and towards deeper learning styles (Hypothesis 4).

\subsection{Method ${ }^{1}$}

\subsubsection{Participants}

To test our hypotheses, we again recruited a sample consisting of 500 US American participants via Amazon MTurk. These participants completed the survey, passed the attention test, and stated to know all six politicians mentioned during the study. However, 14 of them had to be excluded because they finished the whole surveyconsisting of 76 items -in $152 \mathrm{~s}$ or less, which meant that they answered each item in less than $2 \mathrm{~s}$ (not taking reading times for instructions into account). Hence, the final sample size included $N=486$ participants $\left(M_{\text {age }}=27.86, S D_{\text {age }}=7.28\right.$, range: 18-59; 190 females, 296 males). All were college/university students, 454 participants were currently living in the United States, and 366 participants reported that they had at least one graduate parent. Concerning their involvement in politics, 385 participants stated to have voted in the last presidential election in 2016 and 259 participants were members of a political party. Participants were remunerated with US\$ 0.50 .

\subsubsection{Procedure and measures}

The procedure of this second study was very similar to the procedure of the first study: Before starting with the experiment, all participants had to agree to a declaration of consent confirming that they would answer the questions voluntarily and were at least 18 years old. They were informed about the confidential treatment of their data and that they could withdraw from the study at any given time. Then, participants were asked about their demographic information such as age, gender, native language, occupational status, highest educational attainment of their parents, and whether their siblings had graduated from college/university or not. Next, participants' political attitudes, further variables linked to political attitudes, and their attitudes towards difficult and challenging learning strategies were assessed.

3.1.2.1 Political attitudes and further related variables In randomized order, we again assessed political attitudes in a more direct and in a more indirect way. In line with the first study, participants were asked to rate six politicians on a 5-point Likert-like scale ranging from 1 (very unfavorable) to 5 (very favorable) with an additional option 6 (never heard about; see Pfattheicher \& Schindler, 2016). The

\footnotetext{
1 The study was preregistered by AsPredicted (see \#3189; https://aspredicted.org/an8tx.pdf).
} 
politicians rated were Bernie Sanders, Elizabeth Warren, and Joe Biden as representatives for the Democrats, and Donald Trump, Mike Pence, and Mitt Romney as representatives for the Republicans. These six politicians were chosen because they were the three most known Democrats (The Harris Poll, 2019), the two highest ranked Republicans (Ranking Committee, 2019), and the current President of the United States at the time of this second study in November 2019. In line with Study 1, we ran a factorial analysis to test the number of factors underlying the six items assessing favorableness ratings of the politicians. This factor analysis yielded two factors: Factor 1 consisted of the favorableness ratings of the three Republican politicians Donald Trump, Mike Pence, and Mitt Romney (average score of the three items: ratings of Republicans; $\alpha=0.84$ ). Factor 2 consisted of the favorableness ratings of the three Democratic politicians Bernie Sanders, Elizabeth Warren, and Joe Biden (average score of the three items: ratings of Democrats; $\alpha=0.72$ ). A detailed description of this factor analysis is available in Appendix A. Hence, the following analyses will again use the ratings of Democrats and the ratings of Republicans as more indirect assessments of political attitudes. As an addition to Study 1, we then included an open question inquiring about the reasons on which participants based their ratings of the politicians. Thus, we wanted to assess potential further factors that might influence the favorableness ratings additionally to participants' political attitudes.

Unlike in Study 1, we then applied a scale from Carney et al. (2008) to measure participants' self-reported political attitude as the mean score of three items $(\alpha=0.90)$. The first item focused on participants' general political orientation, the second one on social dimensions of political orientation, and the third one on economic dimensions of political orientation. All items were answered on a 5-point Likert-like scale from 1 (extremely liberal) to 5 (extremely conservative).

Based on work from Blais and St-Vincent (2011) and from Norris (2003), we then measured participants' political interest and their perceived importance of politics as further variables that might be linked to political attitudes and our dependent variables: Participants were asked to indicate how interested they are in politics ("Overall, how would you describe your interest in politics?") on a 10-point Likert scale from 1 (not interested at all) to 10 (very interested). In the following, we will refer to this item as political interest. Next, participants indicated how important they perceived politics to be for themselves ("Overall, how would you describe the importance of politics in your life?") on a 10-point Likert scale from 1 (not important at all) to 10 (very important). In the following, we will refer to this item as perceived importance of politics. Additionally, to describe our sample in more detail, participants were then asked whether they had voted in the last presidential election in 2016 and whether they considered themselves to be a member of a political party.

3.1.2.2 Difficult and challenging learning strategies Hereinafter, we assessed our four dependent variables, including participants' attitudes towards different desirable difficulties $(\alpha=0.89)$, towards the use of desirable difficulties at school $(\alpha=0.82)$, towards the preferred difficulty of the learning process $(\alpha=0.77)$, and 
towards deeper learning styles $(\alpha=0.92)$. We used the same measurements as in Study 1.

\subsection{Results}

Table 3 shows descriptive statistics and correlations among the variables measuring political attitudes and attitudes towards difficult and challenging learning strategies. The average of self-reported political attitude $(M=2.96, S D=1.12)$ did not differ from the mean of the used scale $(M=3.00), t(485)=-0.70, p=0.482$. Thus, participants in our sample were neither more liberal nor more conservative as compared to the mean of the scale. However, the ratings of Democrats $(M=3.54, S D=1.04)$ were significantly more favorable than the ratings of Republicans $(M=2.97$, $S D=1.30), t(485)=7.83, p<0.001$. The average of participants' reported political interest $(M=6.94, S D=2.22)$ and their perceived importance of politics $(M=6.85$, $S D=2.29)$ were higher than the mean of the applied scales $(M=5.50$; both $p s<0.001)$. This suggested that our sample was relatively interested in politics and assumed politics to be relatively important in their lives. The correlations reported in Table 3 also served as first evidence for our hypotheses: Unexpectedly, there were no significant correlations among the attitude towards desirable difficulties, participants' self-reported political attitude, the ratings of Republicans, and the ratings of Democrats (all $p s \geq 0.516$; see Table 3). In line with this, we found no significant correlations among participants' attitude towards the use of desirable difficulties at school, self-reported political attitude, the ratings of Republicans, and the ratings of Democrats (all $p s \geq 0.419$; see Table 3 ). Besides, the correlations among the attitude towards the preferred difficulty of the learning process, self-reported political attitude, the ratings of Republicans, and the ratings of Democrats were not significant (all $p s \geq 0.247$; see Table 3). Moreover, participants' attitude towards deeper learning styles was not correlated with their self-reported political attitude, the ratings of Republicans, and the ratings of Democrats (all $p s \geq 0.237$; see Table 3). Summarizing, none of our hypotheses could be supported.

We additionally conducted hierarchical regression analyses on our four dependent variables to respectively test if the effects of self-reported political attitude would change when controlling for the ratings of Republicans, for the ratings of Democrats, for participants' interest in politics, and for their perceived importance of politics. To test Hypothesis 1 in more detail, we conducted hierarchical regression analyses predicting participants' attitude towards desirable difficulties. In a first model, we used the self-reported political attitude as a predictor. $R$ for this regression was not significantly different from zero, $F(1484)=0.002, p=0.962$, and less than $0.10 \%$ $(<0.10 \%$ adjusted) of the variability was explained. Self-reported political attitude was not a significant predictor, $t(484)=0.05, B=0.002, S E=0.04, \beta=0.002$, $p=0.962$. In a second model (see Table 4), the ratings of Republicans and the ratings of Democrats were added as predictors. $R$ for this regression was not significantly different from zero, $F(3482)=0.23, p=0.877$, and could explain $0.10 \%(<0.10 \%$ adjusted) of the variability. This second model did not explain more variance than the first model, $F_{\text {change }}=0.34, p=0.711$. None of the predictors were significant: 


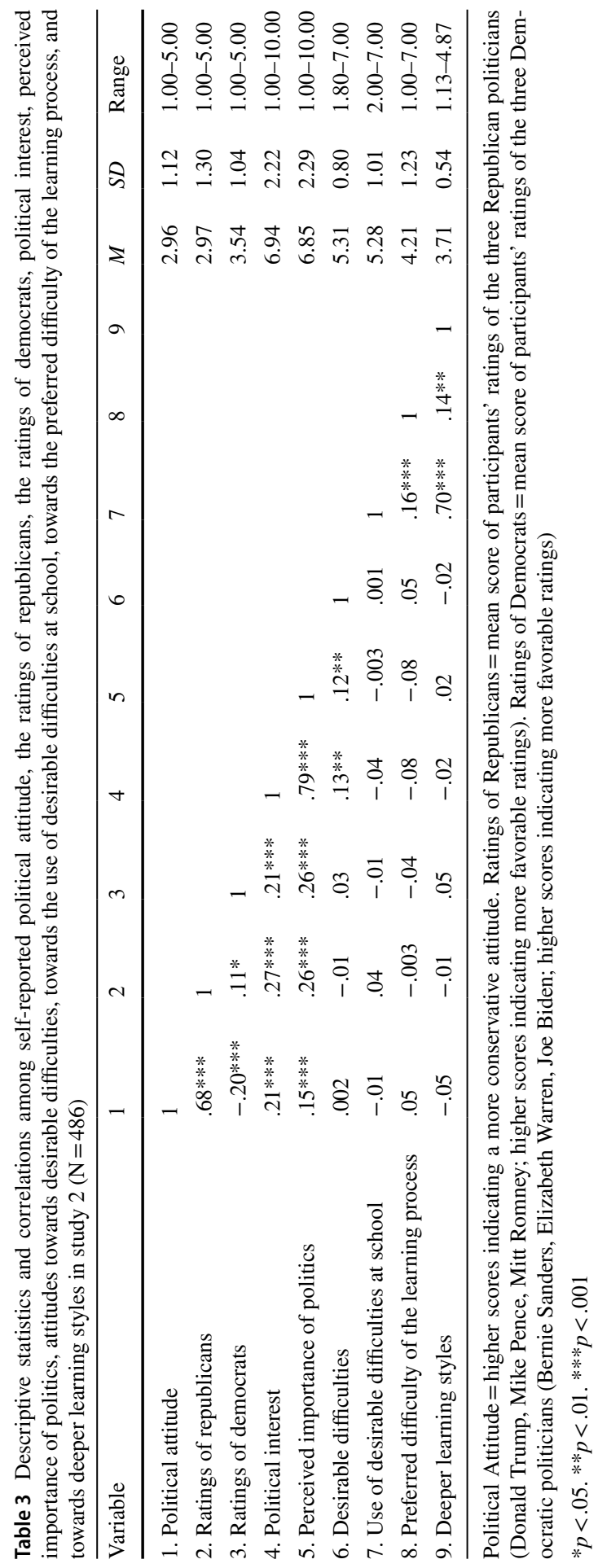




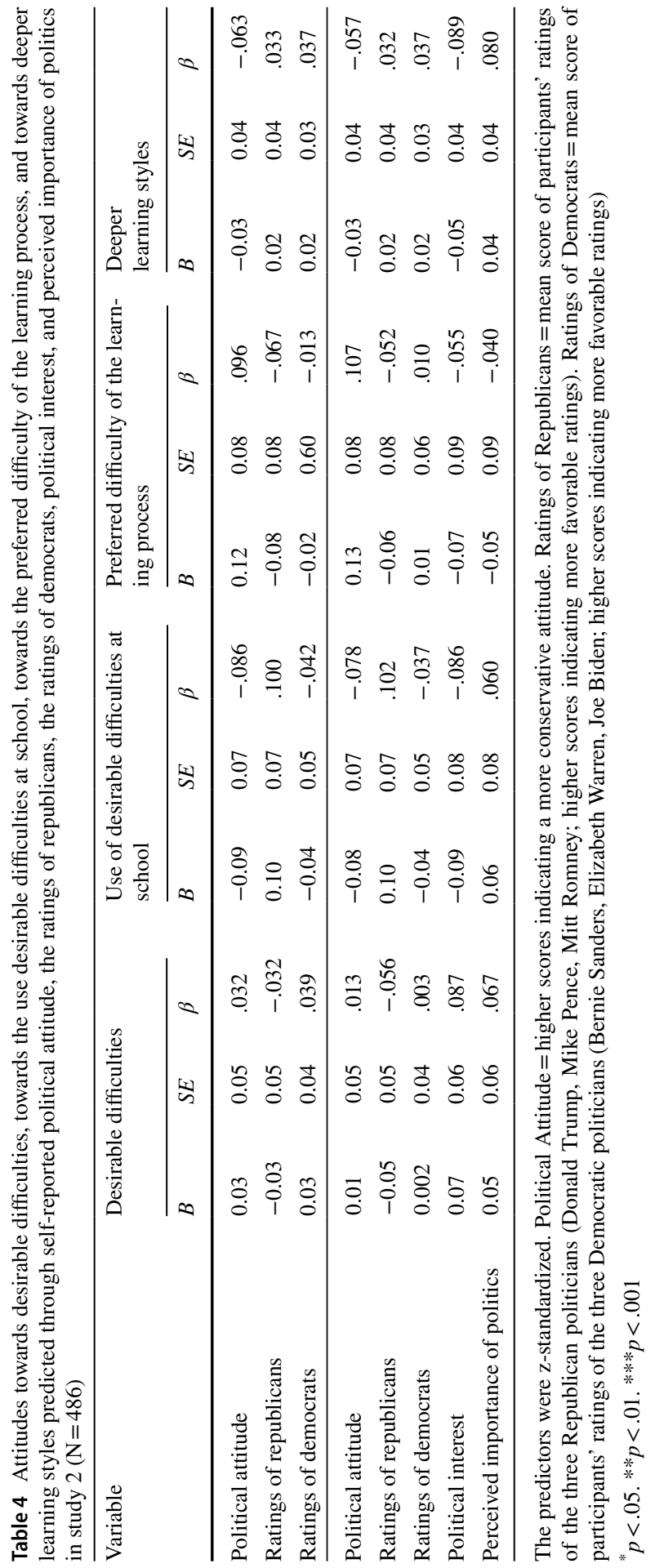


neither self-reported political attitude, $t(482)=0.47, p=0.636$, nor the ratings of Republicans, $t(482)=-0.48, p=0.631$, nor the ratings of Democrats, $t(482)=0.80$, $p=0.427$. In a third model (see Table 4), participants' political interest and their perceived importance of politics were added as predictors. $R$ for this regression was not significantly different from zero, $F(5480)=1.94, p=0.087$, and could explain $2.00 \%$ ( $1.00 \%$ adjusted) of the variability. This third model explained more variance than the second model, $F_{\text {change }}=4.50, p=0.012$. However, none of the predictors were significant: neither the self-reported political attitude, $t(480)=0.19, p=0.848$, nor the ratings of Republicans, $t(480)=-0.48, p=0.399$, nor the ratings of Democrats, $t(480)=0.05, p=0.961$, nor political interest, $t(480)=1.18, p=0.239$, nor perceived importance of politics, $t(480)=0.90, p=0.369$.

To test Hypothesis 2 in more detail, we then conducted hierarchical regression analyses predicting participants' attitude towards the use of desirable difficulties at school. In a first model, we used the self-reported political attitude as a predictor. $R$ for this regression was not significantly different from zero, $F(1484)=0.04$, $p=0.836$, and less than $0.10 \%(<0.10 \%$ adjusted $)$ of the variability was explained. Self-reported political attitude was not a significant predictor, $t(484)=-0.21$, $B=-0.01, S E=0.05, \beta=-0.009, p=0.836$. In a second model (see Table 4), the ratings of Republicans and the ratings of Democrats were added as predictors. $R$ for this regression was also not significantly different from zero, $F(3482)=0.81$, $p=0.487$, and could explain only $0.50 \%(<0.10 \%$ adjusted $)$ of the variability. This second model did not explain more variance than the first model, $F_{\text {change }}=1.20$, $p=0.302$. None of the predictors were significant: neither self-reported political attitude, $t(482)=-1.28, p=0.202$, nor the ratings of Republicans, $t(482)=1.51$, $p=0.132$, nor the ratings of Democrats, $t(482)=-0.84, p=0.400$. In a third model (see Table 4), participants' political interest and their perceived importance of politics were added as predictors. $R$ for this regression was not significantly different from zero, $F(5,480)=0.76, p=0.580$, and could explain $0.80 \%(<0.10 \%$ adjusted $)$ of the variability. This third model did also not explain more variance than the second model, $F_{\text {change }}=0.68, p=0.509$. Again, none of the predictors were significant: neither self-reported political attitude, $t(480)=-1.15, p=0.250$, nor the ratings of Republicans, $t(480)=1.53, p=0.127$, nor the ratings of Democrats, $t(480)=-0.73$, $p=0.465$, nor political interest, $t(480)=-1.16, p=0.248$, nor the perceived importance of politics, $t(480)=0.81, p=0.419$.

To test Hypothesis 3 in more detail, we conducted hierarchical regression analyses predicting participants' attitude towards their preferred difficulty of the learning process. In a first model, we used the self-reported political attitude as a predictor. $R$ for this regression was not significantly different from zero, $F(1484)=1.34$, $p=0.247$, and $0.30 \%(0.10 \%$ adjusted $)$ of the variability was explained. Self-reported political attitude was not a significant predictor, $t(484)=1.16, B=-0.06, S E=0.06$, $\beta=0.053, p=0.247$. In a second model (see Table 4), the ratings of Republicans and the ratings of Democrats were added as predictors. $R$ for this regression was not significantly different from zero, $F(3482)=0.93, p=0.426$, and could explain $0.60 \%(<0.10 \%$ adjusted $)$ of the variability. This second model did not explain more variance than the first model, $F_{\text {change }}=0.73, p=0.485$. Again, none of the predictors were significant: neither political attitude, $t(482)=1.43, p=0.154$, nor the ratings of 
Republicans, $t(482)=-1.02, p=0.311$, nor the ratings of Democrats, $t(482)=-0.27$, $p=0.791$. In a third model (see Table 4), participants' political interest and their perceived importance of politics were added as predictors. $R$ for this regression was not significantly different from zero, $F(5,480)=1.24, p=0.288$, and could explain $1.30 \%(0.20 \%$ adjusted $)$ of the variability. This third model did not explain more variance than the second model, $F_{\text {change }}=1.71, p=0.183$. Again, none of the predictors were significant: neither self-reported political attitude, $t(480)=1.59, p=0.112$, nor the ratings of Republicans, $t(480)=-0.78, p=0.434$, nor the ratings of Democrats, $t(480)=0.19, p=0.850$, nor political interest, $t(480)=-0.74, p=0.460$, nor the perceived importance of politics, $t(480)=-0.54, p=0.590$.

To test Hypothesis 4 in more detail, we conducted hierarchical regression analyses predicting participants' attitude towards deeper learning styles. In a first model, we used the self-reported political attitude as a predictor. $R$ for this regression was not significantly different from zero, $F(1484)=1.13, p=0.288$, and $0.20 \%(<0.10 \%$ adjusted) of the variability was explained. Self-reported political attitude was not a significant predictor, $t(484)=-1.06, B=-0.03, S E=0.02, \beta=-0.048, p=0.288$. In a second model (see Table 4), the ratings of Republicans and the ratings of Democrats were added as predictors. $R$ for this regression was not significantly different from zero, $F(3482)=0.78, p=0.503$, and could only explain $0.50 \%(<0.10 \%$ adjusted) of the variability. This second model did not explain more variance than the first model, $F_{\text {change }}=0.61, p=0.543$. Neither self-reported political attitude, $t(482)=-0.94, p=0.346$, nor the ratings of Republicans, $t(482)=0.50, p=0.617$, nor the ratings of Democrats, $t(482)=0.76, p=0.449$, were significant. In a third model (see Table 4), participants' political interest and their perceived importance of politics were added as predictors. $R$ for this regression was not significantly different from zero, $F(5480)=0.77, p=0.572$, and could explain $0.80 \%(<0.10 \%$ adjusted) of the variability. This third model did not explain more variance than the second model, $F_{\text {change }}=0.75, p=0.474$. Again, none of the predictors were significant: neither self-reported political attitude, $t(480)=-0.84, p=0.402$, nor the ratings of Republicans, $t(480)=0.49, p=0.627$, nor the ratings of Democrats, $t(480)=0.73$, $p=0.465$, nor political interest, $t(480)=-1.19, p=0.233$, nor perceived importance of politics, $t(480)=1.08, p=0.281$. Hence, none of our hypotheses was supported. Moreover, none of the presented results differed when controlling for participants' age or gender.

\subsection{Discussion}

Study 2 aimed at replicating the findings of Study 1 and again explored the linkages among participants' political attitudes and their attitudes towards difficult and challenging learning strategies. Unlike Study 1, none of the hypotheses were supported by our data: None of our assessments of political attitudes were significantly correlated with any of the dependent variables and the hierarchical regression analyses also found neither significant nor varying results. This raises the question whether the significant findings of Study 1 or the non-significant findings of this second study were found randomly. Notably, although adding political interest 
and perceived importance of politics as further predictors in the hierarchical regression analyses did not yield significant effects (see Table 4), both variables were significantly correlated with a more positive attitude towards desirable difficulties (see Table 3). The regression model including these two variables as further predictors also explained more variance than the model without them, thus, highlighting the relevance of adding these two variables in future work.

Taking a closer look at the three measurements of political attitudes, we found that the self-reported political attitude and the ratings of Republicans were strongly and positively correlated; thus, indicating that both assess more conservative political attitudes but are still distinct constructs. Self-reported political attitude and the ratings of Democrats were again negatively correlated, but only weakly. Notably, the ratings of Republicans and the ratings of Democrats were, contrary to Study 1, weakly but positively correlated with each other (see Table 3). These observations again raise the question what the different measurements of political attitudes actually assess - in addition to or beyond conservative or liberal political attitudes. Our open question regarding participants' reasons for their ratings of the politicians showed indeed that not all ratings were based on participants' political attitudes and the respective politicians' political orientations but also on their personalities, their media presence, their behavior, or how likeable participants perceived them to be. In line with this, the conducted factorial analysis (see Appendix A) again showed that the two resulting factors indicating politicians' political party did not completely explain all variability among the six items. Additionally, the self-reported political attitude, the ratings of Republicans, and the ratings of Democrats were positively correlated with participants' interest in politics and their perceived importance of politics (see Table 3). Thus, it is relevant to include the different measurements of political attitudes as well as participants' interest in politics and their perceived importance of politics in future studies. Furthermore, Table 3 shows that our four dependent variables were, contrary to Study 1 , only partially significantly correlated with each other. This is surprising since these measurements were designed to assess similar constructs in terms of difficult and challenging learning strategies. Hence, all in all, we decided to replicate this second study.

\section{Study 3}

Studies 1 and 2 yielded different results regarding linkages among participants' political attitudes and their attitudes towards difficult and challenging learning strategies. Study 3 was therefore conducted to again test our hypotheses and to explore whether the results of Study 1 or the results of Study 2 can be supported. Aiming to make a more reliable statement and to be able to detect even smaller effects, we chose a larger sample size compared to our previous studies. Thus, Study 3 was designed to offer even more meaningful evidence for the assumed linkages including not only the largest but also the most recent sample of our three studies. Again, we assumed the same four hypotheses as in Study 1 and Study 2, predicting a more conservative political attitude to be correlated with more positive attitudes 
towards desirable difficulties (Hypothesis 1), towards the use of desirable difficulties at school (Hypothesis 2), towards the preferred difficulty of the learning process (Hypothesis 3), and towards deeper learning styles (Hypothesis 4).

\subsection{Method $^{2}$}

\subsubsection{Participants}

An a priori power analysis with $\mathrm{G}^{*}$ Power (Faul et al., 2009) revealed a needed sample size of $N=542$ to detect a small effect $(r=0.12)$ given a power of 0.80 and an alpha level of 0.05 . Thus, we recruited a sample consisting of 580 US American participants via Amazon MTurk. Nine participants had to be excluded because they did not answer all question. The remaining 571 participants finished the survey, passed the attention test, and stated to know all six politicians mentioned during the study. However, 15 of these participants had to be excluded because they finished the whole survey-consisting of 73 items and instructions-in 146 s or less. This meant that they answered each item in (less than) $2 \mathrm{~s}$ (not taking reading times for instructions into account). Hence, the final sample included $N=556$ participants $\left(M_{\text {age }}=30.31, S D_{\text {age }}=10.31\right.$, range: $17-69 ; 239$ females, 315 males, two diverse $)$. All were college/university students, and 514 participants were currently living in the United States. Concerning their involvement in politics, 377 participants stated to have voted in the last presidential election in 2016 and 279 participants were members of a political party. Participants were remunerated with US $\$ 0.50$.

\subsubsection{Procedure and measures}

Study 3 was conducted in July 2020. Before starting, all participants had to agree to a declaration of consent confirming that they answered the questions voluntarily and were at least 18 years old. They were informed about the confidential treatment of their data and that they could withdraw from the study at any given time. Since this third study was a replication of Study 2, the applied procedure and methods were identical with the ones used in Study 2 except for two differences: First, we excluded the inquiry about the academic background of participants' parents and siblings. Second, we changed the open question about underlying reasons for participants' ratings of the politicians into a single choice question. The answer options ("political orientation", "sympathy", "gut feeling", "personalities", and "other reasons") were derived from participants' answers to the respective open-ended question in Study 2.

In line with Study 1 and Study 2, we again conducted a factor analysis regarding the favorableness ratings of the six politicians, which again yielded two factors: Factor 1 consisted of the favorableness ratings of the three Republican politicians Donald Trump, Mike Pence, and Mitt Romney (average score of the three items: ratings

2 The study was preregistered by AsPredicted (see \#44269; https://aspredicted.org/bh32q.pdf). 
of Republicans; $\alpha=0.80)$. Factor 2 consisted again of the favorableness ratings of the three Democratic politicians Bernie Sanders, Elizabeth Warren, and Joe Biden (average score of the three items: ratings of Democrats; $\alpha=0.75$ ). See Appendix A for a detailed description of this factor analysis.

\subsection{Results}

Table 5 shows descriptive statistics and correlations among the variables measuring political attitudes and attitudes towards difficult and challenging learning strategies. The average of self-reported political attitude $(M=2.86, S D=1.11)$ significantly differed from the mean of the used scale $(M=3.00), t(555)=-2.90, p=0.004$. Thus, participants in our sample reported to be rather more liberal than conservative. The ratings of Democrats $(M=3.56, S D=1.04)$ were also more favorable than the ratings of Republicans $(M=2.99, S D=1.24), t(555)=8.73, p<0.001$. The question about the reasons for these ratings showed that 324 participants based their ratings on the politicians' political orientation, 139 reported that the politicians' personalities were most important, 50 chose "gut feeling", 24 chose "other reasons", and 19 reported that they rated the politicians according to their sympathy. The average of participants' reported political interest $(M=6.89, S D=2.16)$ was significantly higher than the mean of the used scale $(M=5.50), t(555)=15.15, p<0.001$. The same applied to their perceived importance of politics $(M=6.75, S D=2.28)$, which was also significantly higher than the mean of the used scale $(M=5.50), t(555)=12.95, p<0.001$. Therefore, our sample appeared to be relatively interested in politics and assumed politics to be relatively important in their lives.

The correlations reported in Table 5 also served as first evidence for our hypotheses: Participants' attitude towards desirable difficulties was positively related to self-reported political attitudes $(r=0.16, p<0.001)$ and to the ratings of Republicans $(r=0.22, p<0.001)$. This indicated that a more conservative political attitude was associated with a more positive attitude towards desirable difficulties. Unexpectedly, participants' attitude towards desirable difficulties was also positively related to the ratings of Democrats $(r=0.30, p<0.001)$. The attitude towards the use of desirable difficulties at school was also positively related to political attitude ( $r=0.18, p<0.001)$, to the ratings of Republicans $(r=0.23, p<0.001)$, and to the ratings of Democrats $(r=0.22, p<0.001)$. The same applied to participants' attitude towards their preferred difficulty of the learning process, which was also positively related to political attitude $(r=0.36, p<0.001)$, the ratings of Republicans $(r=0.38$, $p<0.001)$, and the ratings of Democrats $(r=0.11, p=0.013)$. Also, participants' attitude towards deeper learning styles was positively related to political attitude ( $r=0.15, p<0.001)$, to the ratings of Republicans $(r=0.21, p<0.001)$, and to the ratings of Democrats $(r=0.22, p<0.001)$. Summarizing, we found support for all our hypotheses, indicating that more conservative political attitudes are related to more positive attitudes towards difficult and challenging learning strategies. However, opposing our hypotheses, the ratings of Democrats were also positively related to more positive attitudes towards difficult and challenging learning strategies. 


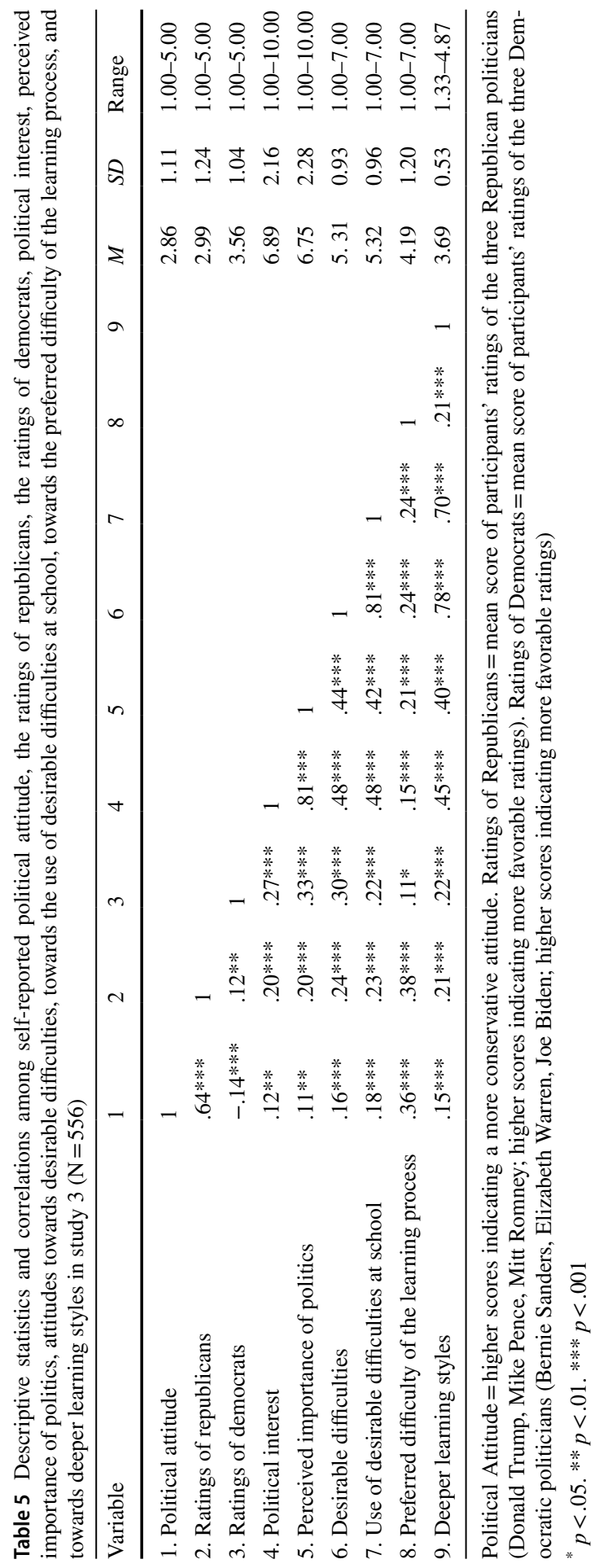


We additionally conducted hierarchical regression analyses on our four dependent variables to respectively test if the effects of self-reported political attitude would change when controlling for the ratings of Republicans, for the ratings of Democrats, for participants' interest in politics, and for their perceived importance of politics. Consequently, to test Hypothesis 1 in more detail, we conducted hierarchical regression analyses predicting participants' attitude towards desirable difficulties. In a first model, we used the self-reported political attitude as a predictor. $R$ for this regression was significantly different from zero, $F(1554)=13.78, p<0.001$, and altogether $2.40 \%$ (2.30\% adjusted) of the variability was explained. Self-reported political attitude was a significant predictor, $t(554)=3.71, B=0.15, S E=0.04$, $\beta=0.156, p<0.001$. In a second model (see Table 6), the ratings of Republicans and the ratings of Democrats were added as predictors. $R$ for this regression was significantly different from zero, $F(3552)=28.88, p<0.001$, and could explain $13.60 \%$ (13.10\% adjusted) of the variability. This second model explained more variance than the first model, $F_{\text {change }}=35.57, p<0.001$. Self-reported political attitude, $t(552)=2.45, p=0.015$, the ratings of Republicans, $t(552)=1.99, p=0.048$, and the ratings of Democrats, $t(552)=7.38, p<0.001$, were significant predictors. In a third model (see Table 6), participants' political interest and their perceived importance of politics were added as predictors. $R$ for this regression was significantly different from zero, $F(5550)=43.86, p<0.001$, and could explain $28.50 \%$ (27.90\% adjusted) of the variability. This third model explained more variance than the second model, $F_{\text {change }}=57.47, p<0.001$. Self-reported political attitude was a significant predictor, $t(550)=1.97, p=0.049$. The ratings of Republicans had no significant effect, $t(550)=1.16, p=0.247$, while the ratings of Democrats did, $t(550)=4.68, p<0.001$. Political interest was also a significant predictor, $t(550)=5.46, p<0.001$, but not the perceived importance of politics, $t(550)=1.49, p=0.136$.

To test Hypothesis 2 in more detail, we then conducted hierarchical regression analyses predicting participants' attitude towards the use of desirable difficulties at school. In a first model, we used the self-reported political attitude as a predictor. $R$ for this regression was significantly different from zero, $F(1554)=18.47, p<0.001$, and $3.20 \%(3.10 \%$ adjusted) of the variability was explained. Self-reported political attitude was a significant predictor, $t(554)=4.30, B=0.17, S E=0.04, \beta=0.180$, $p<0.001$. In a second model (see Table 6), the ratings of Republicans and the ratings of Democrats were added as predictors. $R$ for this regression was significantly different from zero, $F(3,552)=20.92, p<0.001$, and explained $10.20 \%(9.70 \%$ adjusted) of the variability. This second model explained more variance than the first model, $F_{\text {change }}=21.46, p<0.001$. All predictors were significant: political attitude, $t(552)=2.54, p=0.011$, the ratings of Republicans, $t(552)=2.12, p=0.034$, and the ratings of Democrats, $t(552)=5.41, p<0.001$. In a third model (see Table 6), participants' political interest and their perceived importance of politics were added as predictors. $R$ for this regression was significantly different from zero, $F(5550)=38.60$, $p<0.001$, and could explain $26.00 \%$ (25.30\% adjusted) of the variability. This third model explained more variance than the second model, $F_{\text {change }}=58.57, p<0.001$. Self-reported political attitude was a significant predictor, $t(550)=2.08, p=0.038$. The ratings of Republicans had no significant effect, $t(550)=1.31, p=0.191$. The ratings of Democrats was significant, $t(550)=2.70, p=0.007$. Political interest was 


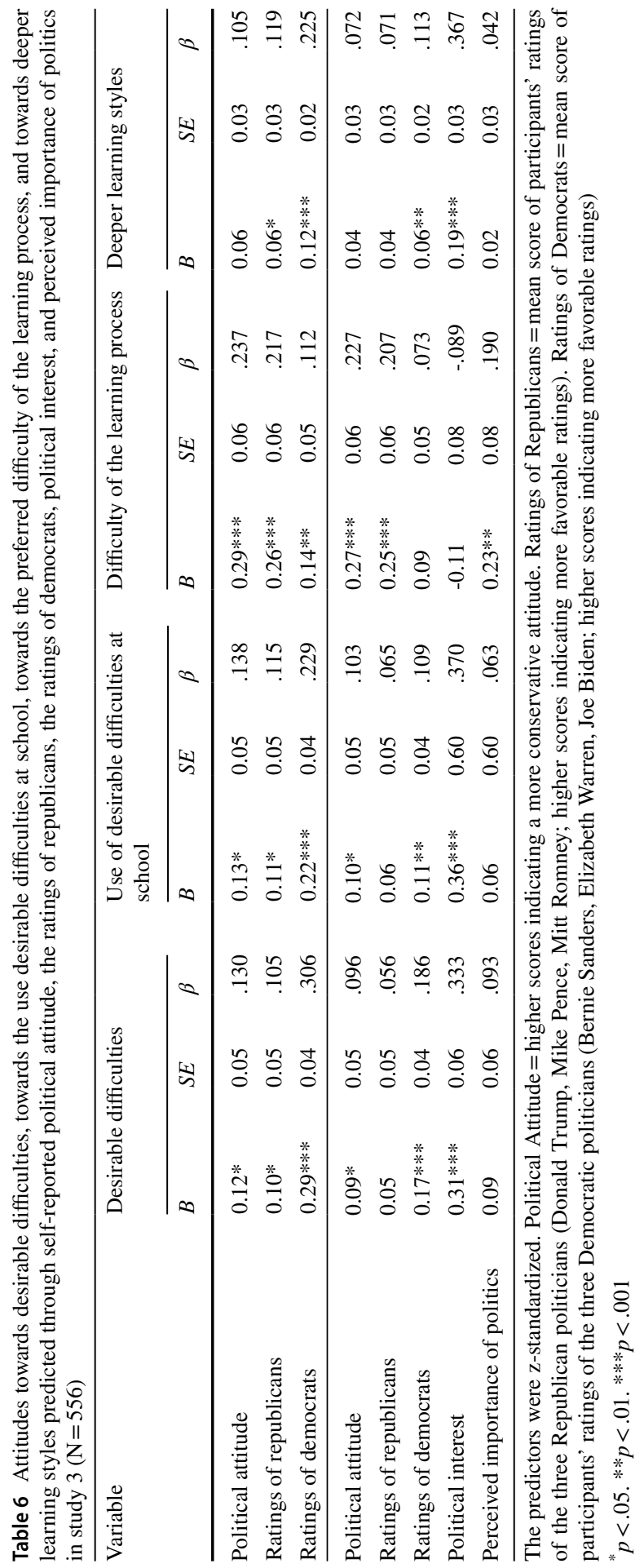


also significant, $t(550)=5.95, p<0.001$, but not the perceived importance of politics, $t(550)=0.99, p=0.323$.

To test Hypothesis 3 in more detail, we conducted hierarchical regression analyses predicting participants' attitude towards their preferred difficulty of the learning process. In a first model, we used the self-reported political attitude as a predictor. $R$ for this regression was significantly different from zero, $F(1554)=82.22, p<0.001$, and $12.90 \%$ (12.80\% adjusted) of the variability was explained. Self-reported political attitude was a significant predictor, $t(554)=9.07, B=0.43, S E=0.05, \beta=0.359$, $p<0.001$. In a second model (see Table 6), the ratings of Republicans and the ratings of Democrats were added as predictors. $R$ for this regression was significantly different from zero, $F(3552)=40.25, p<0.001$, and could explain $17.90 \%(17.50 \%$ adjusted) of the variability. This second model explained more variance than the first model, $F_{\text {change }}=16.91, p<0.001$. Again, all predictors were significant: self-reported political attitude, $t(552)=4.57, p<0.001$, the ratings of Republicans, $t(552)=4.19$, $p<0.001$, and the ratings of Democrats, $t(552)=2.78, p=0.006$. In a third model (see Table 6), participants' political interest and their perceived importance of politics were added as predictors. $R$ for this regression was significantly different from zero, $F(5550)=26.58, p<0.001$, and could explain $19.50 \%$ (18.70\% adjusted) of the variability. This third model explained more variance than the second model, $F_{\text {change }}=5.17, p=0.006$. Self-reported political attitude, $t(550)=4.40, p<0.001$, and the ratings of Republicans, $t(550)=4.02, p<0.001$, were significant predictors. The rating of Democrats was not significant, $t(550)=1.74, p=0.083$. Political interest was also not significant, $t(550)=-1.37, p=0.173$, while the perceived importance of politics had a significant effect, $t(550)=2.88, p=0.004$.

To test Hypothesis 4 in more detail, we also conducted hierarchical regression analyses predicting participants' attitude towards deeper learning styles. In a first model, we used the self-reported political attitude as a predictor. $R$ for this regression was significantly different from zero, $F(1554)=12.72, p<0.001$, and $2.20 \%$ $(2.10 \%$ adjusted) of the variability was explained. Self-reported political attitude was a significant predictor, $t(554)=3.57, B=0.08, S E=0.02, \beta=0.150, p<0.001$. In a second model (see Table 6), the ratings of Republicans and the ratings of Democrats were added as predictors. $R$ for this regression was significantly different from zero, $F(3552)=18.46, p<0.001$, and could explain $9.10 \%$ (8.60\% adjusted) of the variability. This second model explained more variance than the first model, $F_{\text {change }}=20.88, p<0.001$. The self-reported political attitude did not remain significant, $t(552)=1.92, p=0.055$. However, the ratings of Republicans, $t(552)=2.18$, $p=0.030$, and the ratings of Democrats, $t(552)=5.29, p<0.001$, had significant effects. In a third model (see Table 6), participants' political interest and their perceived importance of politics were added as predictors. $R$ for this regression was significantly different from zero, $F(5550)=33.75, p<0.001$, and could explain $23.50 \%$ $(22.80 \%$ adjusted) of the variability. This third model explained more variance than the second model, $F_{\text {change }}=51.61, p<0.001$. Self-reported political attitude, $t(550)=1.44, p=0.151$, and the ratings of Republicans, $t(550)=1.41, p=0.160$, had no significant effect. The ratings of Democrats, $t(550)=2.74, p=0.006$, and political interest, $t(550)=5.82, p<0.001$, were significant predictors. The perceived 
importance of politics was not significant, $t(550)=0.65, p=0.513$. None of the presented results would differ when controlling for participants' age or gender.

\subsection{Discussion}

Study 3 was conducted to test whether the previously found results of Study 1 or of Study 2 could be replicated. The correlational analyses of Study 3 supported all hypotheses and thus, in turn, the findings of Study 1. Notably, the findings of this third study even extended the results of Study 1: The correlations and the hierarchical regression analyses showed that attitudes towards difficult and challenging learning strategies were not only positively linked to self-reported conservative political attitude and to more favorable ratings of Republicans, but also to more favorable ratings of Democrats indirectly indicating a more liberal political attitude. More precisely, our results showed that the hierarchical regression models using the selfreported political attitude, the ratings of Republicans, the ratings of Democrats, participants' interest in politics, and their perceived importance of politics as predictors best explained our respective dependent variables. Concerning participants' attitude towards desirable difficulties, the self-reported political attitude, the ratings of Democrats, and political interest remained significant and positive predictors. Notably, the regression coefficient of the ratings of Democrats was descriptively even stronger than the regression coefficient of the self-reported political attitude. Furthermore, when predicting the attitude towards the use of desirable difficulties at school, the self-reported political attitude, the ratings of Democrats, and political interest again remained significant. Concerning participants' attitude towards their preferred difficulty of the learning process, the self-reported political attitude, the ratings of Republicans, and participants' perceived importance of politics remained significant predictors. Finally, when predicting the attitude towards deeper learning styles, only the ratings of Democrats and interest in politics were significant predictors.

Summarizing, these results highlight that both the self-reported political attitude as an indicator of conservative political attitudes as well as the ratings of Democrats as an indicator of liberal political attitudes were able to predict participants' attitudes towards desirable difficulties and towards the use of desirable difficulties at school. Concerning the attitude towards deeper learning styles, only the ratings of Democrats, and thus the rather liberal political attitudes, were influential (see Table 6). These findings indicate that more liberal political attitudes might be linked to more positive attitudes towards the active, cognitive, and stimulating aspects of desirable difficulties. This assumption is in line with previous work finding linkages among high need for cognition and liberal political attitudes (Condra, 1992) as well as between high need for cognition and positive attitudes towards desirable difficulties (Weissgerber et al., 2018). In contrast, concerning the attitude towards the preferred difficulty of the learning process, only the ratings of Republicans, and thus only the more conservative political attitudes, were significant predictors (see Table 6). Hence, more conservative political attitudes seem to be linked to more positive attitudes towards the difficult, demanding, and challenging aspects of desirable 
difficulties. This assumption is in line with our argumentation regarding the world view of a hard-working mankind, which is traditionally represented by the Republican party (Republican National Committee, 2016; see our introduction section).

Moreover, regarding the applied measurements, contrary to Study 2 but in line with Study 1, all dependent variables were significantly correlated with each other (see Table 5). This supported the validity of the different measurements of difficult and challenging learning strategies. Again, self-reported political attitude was strongly and positively related to the ratings of Republicans, but only weakly negatively correlated with the ratings of Democrats. There was also a weak but positive linkage between the ratings of Republicans and the ratings of Democrats. This again indicated that self-reported political attitude and the ratings of the politicians as more indirect assessments of political attitudes were not identical. Moreover, favorable views of the politicians were also linked to participants' political interest and to their perception of political importance. In line with this, our applied question regarding participants' main reason for their ratings of the politicians again revealed that other factors beyond politicians' political orientations influenced participants' ratings. These assumptions have already been taken up by previous research describing that such factors could be politicians' (physical) attractiveness, their familiarity, their personalities, their competence, their responses to personal attacks, their gender, their media coverage, and individuals' self-interest concerning the politicians' programs (see e.g., Bligh et al., 2012; Budesheim \& DePaola, 1994; Cisłak \& Wojciszke, 2006; Frimer \& Skitka, 2018; Garzia, 2011; Heflick \& Goldenberg, 2011; Verhulst et al., 2010). Thus, in addition to participants' political interest and to their perception of political importance, further variables might also be important for attitudes towards difficult and challenging learning strategies and could therefore be additionally included in future studies.

\section{General discussion}

The present work was conducted to test linkages among political attitudes and attitudes towards difficult and challenging learning strategies. This linkage between education and politics is in general known to be of great relevance because politics and education affect each other and because educational policies are usually created by politicians belonging to different political parties. Being interested in students' political attitudes and their perceptions of and attitudes on learning strategies, we were not able to find previous research in this field. This is why we aimed at filling this gap with the series of studies at hand taking the United States as a starting point. More precisely, we were interested in whether students' conservative political attitude was linked to their attitudes concerning desirable difficulties, the use of desirable difficulties at school, the preferred difficulty of the learning process, and deeper learning styles. Because these learning strategies should be perceived as effortful and difficult, which fits more conservative world views, we expected a positive relationship between more conservative political attitudes and attitudes towards such difficult and challenging learning strategies. In line with this assumption, Study 1 indeed found positive 
correlations between conservative political attitudes and attitudes towards difficult and challenging learning strategies. This finding could not be supported by Study 2, which found no significant linkages among the assessed variables. Thereupon, Study 3 showed that self-reported political attitude, favorableness ratings of Republicans, and favorableness ratings of Democrats were significantly linked to more positive attitudes towards difficult and challenging learning strategies. Additionally, in this third study, positive correlations of our dependent variables and participants' interest in politics and their perceived importance of politics were found: The hierarchical regression analyses including these two predictors could continuously explain more variance than the respective models without these two variables.

In sum, the results of the three conducted studies differed from each other, thereby raising the question about their validity, significance, and evaluation. In general, Study 3 included the largest sample. Thus, this study was able to detect even smaller effects, optimized some smaller limitations of the previous studies, yielded bigger correlations, explained more variance, and included the most recent data in comparison with Studies 1 and 2. Consequently, we assume that Study 3 included the most valid and reliable data and thus attach more emphasis on the results of this last study.

All in all, the relationships among conservative political attitudes and more positive attitudes towards difficult and challenging learning strategies are in line with the argumentations and empirical findings presented above. For instance, as stated in their platform, the Republican party's aim is “to attract the best talent to the classroom" (Republican National Committee, 2016, p.40). Hence, as a party of order (Gerring, 2001) with "higher expectations for all students" (Republican National Committee, 2016, p.40), the Republicans create an image of hard work and performance. When desirable difficulties are regarded as strict and demanding learning strategies, they thus fit this conservative world view. This becomes particularly clear in Study 3 showing that both a more conservative self-reported political attitude and more favorable ratings of Republicans simultaneously predicted participants' attitude towards the preferred difficulty of the learning process but not to the other dependent variables. In comparison, concerning the other three dependent variables in Study 3, the ratings of Democrats indicating a more liberal political attitude yielded descriptively stronger regression coefficients compared to the coefficients of the self-reported political attitude or of the ratings of Republicans (both were even not continuously significant). This leads us to assume that more liberal minded participants perceived the presented desirable difficulties as well as difficult and challenging learning strategies more as helpful strategies trying to improve learning outcomes and as high-quality learning strategies for everyone (see e.g., Democratic Platform Committee, 2016). Thus, it is possible that individuals with different political attitudes focus on different aspects of desirable difficulties and difficult and challenging learning strategies: In that light, some (the more conservative minded students) might focus more on the difficult and challenging aspects, whereas others (the more liberal minded students) might focus more on the desirable and beneficial aspects. Moreover, as indicated above, we propose that political interest and perceived importance of 
politics should be included in future work because of their effects on attitudes towards difficult and challenging learning strategies in the hierarchical regression analyses. Thus, irrespective of political orientation, it seems appropriate to further explore the role of political interest and perceived importance of politics in the educational context. Future work should try to replicate our findings in this respect and take a more detailed look at the observed correlations and the underlying causalities.

\subsection{Strengths, limitations, and future research}

Apart from these more content-related conclusions, we also want to take a look at the applied methods of our work and, for instance, their strengths: For a better understanding and a preferably extensive exploration of participants' attitudes towards difficult and challenging learning strategies in the academic context, we applied four different measurements. These enabled us to not only assess students' attitude towards desirable difficulties, but also their attitudes towards the use of desirable difficulties at school, towards the preferred difficulty of the learning process, and towards deeper learning styles. In turn, this provided us with a high content validity. The same applies to the measurements of participants' political attitudes using the self-reported political attitude as well as the ratings of the six politicians represented by three Democrats and three Republicans. These two ways of measuring political attitudes were correlated with each other and correlated differently with our dependent variables, thus, highlighting the distinctiveness of the variables indicating political attitudes. Throughout the course of our three studies, we assumed that the ratings of the politicians might additionally assess further variables other than solely and purely participants' political attitudes. We started to explore this question by including participants' political interest and their perceived importance of politics in the statistical analyses and found significant relationships. Hence, we propose that future work could build up on these considerations. We also suggest that it is valuable to use both sorts of assessments of political attitudes-self-reports and favorableness ratings - in such future works because the scales are short and can be easily applied. Through these findings, our work therefore makes methodological contributions to the measurements of the two constructs political attitudes and attitudes toward difficult learning, which should be valuable for future research. Apart from these valuable aspects of our work, there are also limitations as well as more resulting ideas for future work that we want to highlight. For instance, one limitation of our studies is that we were only able to observe correlations regarding participants' attitudes towards politics and difficult and challenging learning strategies. Thus, causal analyses of the found effects would still be advantageous to get to a better understanding of the underlying dynamics. The same applies to further possible links among political attitudes and attitudes as well as behaviors concerning education: For instance, while our studies only focused on students' attitudes towards difficult and challenging learning strategies, it is also interesting to explore the linkage between political attitudes and, among others, students' judgments of learning processes, their decisions regarding universities, their use of certain learning strategies, 
or their persistence and effort while learning. Hence, future work could try to test causal relationships and further dependent variables beyond the assessed attitudes in our studies. In addition, future work should consider variables that might moderate or mediate the relationship between political attitudes and attitudes towards desirable difficulties, their use at school, the preferred difficulty of the learning process, and deeper learning styles. Such variables could be, among others, social-cognitive motives or individuals' personality traits: For instance, previous research found positive correlations between the personality traits extraversion and conscientiousness and a more conservative political attitude (Carney et al., 2008; Sibley et al., 2012; Soldz \& Vaillant, 1999). Similar findings could also be obtained when focusing on European countries (e.g., Krieger et al., 2019; Schoen \& Schumann, 2007; Vecchione et al., 2011). Interestingly, conscientiousness has also been found to be linked to self-regulated learning and to academic achievement (Eilam et al., 2009) as well as to active learning (Bakker et al., 2012). Hence, future research could investigate the impact of further personality traits on students' attitudes towards difficult and challenging learning strategies. Importantly, our research solely focused on the United States although the linkage between politics and learning is equally important across borders. Consequently, future research in other countries with different political systems is needed to explore the relationships between political attitudes, desirable difficulties and learning on a transnational level. Additionally, it would be valuable to attain more recent data in the United States since the political leaderships have changed in the interim. Hence, also further replications of our work in the United States would be valuable. In line with these considerations and due to the general lack of previous research on this topic, the present studies can be regarded as first approaches towards the extensive exploration of the topic at hand. Our studies are hence stimulating and provide a unique starting point for future research investigating the presented research topic in more detail.

\subsection{Conclusion}

The present studies indicate a relationship between students' political attitudes and their attitudes towards desirable difficulties, the use of desirable difficulties at school, the preferred difficulty of the learning process, and deeper learning styles; insofar as that a self-reported more conservative attitude was associated with more positive attitudes towards these difficult and challenging learning strategies. Notably, more favorable ratings of Republicans and of Democrats-indirectly indicating more conservative as well as more liberal political attitudes-were also linked to more positive attitudes towards these variables. Our work therefore made a first step towards the investigation of the relationship between political attitudes and attitudes towards difficult and challenging learning strategies from the perspective of college/university students. Given that successful long-term learning and higher academic achievements are some of the most 
important goals of (higher) education, but that students often have misconceptions regarding the best ways to achieve these goals, it seems extremely valuable to investigate which student characteristics are linked to favorable views of difficult learning strategies. Hence, our work highlights that research regarding attitudes towards learning strategies should also focus on political attitudes of the respective learners even though this might not be the learner characteristics that is typically or automatically thought of. Our work also indicates that it could be helpful to highlight different aspects of desirable difficulties (e.g., the effort or hard work that is needed to solve them successfully or the innovative or creative approach that intends to increase students' durable learning outcomes) when describing their advantages to students with different political attitudes. The present research thereby connects two especially important research domains-desirable difficulties and political attitudes-that had until now not been simultaneously considered. In addition, our research provides a methodological contribution to how political attitudes can be measured and shows that even more variables additionally to direct and indirect measurements can be worth exploring. Thus, the present research and the thereby raised research issues are surely stimulating for future work. In turn, more research is needed to further replicate our findings, to broaden them, and to test potentially underlying theories.

\section{Appendices}

\section{Appendix A: factor analyses of the favorableness ratings of the six politicians in the three studies}

\section{Study 1: factor analysis with varimax rotation}

We conducted a factor analysis with varimax rotation to test the factor structure of the six items asking for favorableness ratings of the six politicians Mike Pence, Donald Trump, Paul Ryan, Bernie Sanders, Hilary Clinton, and Elizabeth Warren. The eigen values and a scree plot yielded two factors explaining a total of $72.21 \%$ of the variance of all six items (see Table 7). Factor 1 consisted of the three items assessing favorableness ratings of the three Republican politicians Mike Pence, Donald Trump, and Paul Ryan (ratings of Republicans; $\alpha=0.854 ; 45.72 \%$ of explained variance, eigen value $=2.74$ ). Factor 2 consisted of the three items assessing favorableness ratings of the three Democratic politicians Bernie Sanders, Hilary Clinton, and Elizabeth Warren (ratings of Democrats; $\alpha=0.714 ; 26.50 \%$ of explained variance, eigen value $=1.59$ ). 
Table 7 Factor loadings for factor analysis with varimax rotation of the favorableness ratings of the six politicians in study 1

\begin{tabular}{lll}
\hline Variable & 1 & 2 \\
\hline Mike Pence & .911 & -.140 \\
Donald Trump & .845 & -.202 \\
Paul Ryan & .859 & .032 \\
Bernie Sanders & -.315 & .719 \\
Hilary Clinton & .046 & .791 \\
Elizabeth Warren & -.082 & .859 \\
\hline
\end{tabular}

\section{Study 2: factor analysis with varimax rotation}

We conducted a factor analysis with varimax rotation to test the factor structure of the six items asking for favorableness ratings of the six politicians Mike Pence, Donald Trump, Mitt Romney, Bernie Sanders, Elizabeth Warren, and Joe Biden. The eigen values and a scree plot yielded two factors explaining a total of 72.68\% of the variance of all six items (see Table 8). Factor 1 consisted of the three items assessing favorableness ratings of the three Republican politicians Mike Pence, Donald Trump, and Mitt Romney (ratings of Republicans; $\alpha=0.837 ; 41.05 \%$ of explained variance, eigen value $=2.463$ ). Factor 2 consisted of the three items assessing favorableness ratings of the three Democratic politicians Bernie Sanders, Elizabeth Warren, and Joe Biden (ratings of Democrats; $\alpha=0.718 ; 31.63 \%$ of explained variance, eigen value $=1.90)$.

Table 8 Factor loadings for factor analysis with varimax rotation of the favorableness ratings of the six politicians in study 2

\begin{tabular}{lll}
\hline Variable & 1 & 2 \\
\hline Mike Pence & .917 & .014 \\
Donald Trump & .876 & -.119 \\
Mitt Romney & .797 & .318 \\
Bernie Sanders & -.210 & .836 \\
Elizabeth Warren & .092 & .821 \\
Joe Biden & .228 & .724 \\
\hline
\end{tabular}




\section{Study 3: factor analysis with varimax rotation}

We conducted another factor analysis with varimax rotation to test the factor structure of the six items asking for favorableness ratings of the six politicians Mike Pence, Donald Trump, Mitt Romney, Bernie Sanders, Elizabeth Warren, and Joe Biden. The eigen values and a scree plot yielded two factors explaining a total of $73.03 \%$ of the variance of all six items (see Table 9). Factor 1 consisted of the three items assessing favorableness ratings of the three Republican politicians Mike Pence, Donald Trump, and Mitt Romney (ratings of Republicans; $\alpha=0.804 ; 41.18 \%$ of explained variance, eigen value $=2.471$ ). Factor 2 consisted of the three items assessing favorableness ratings of the three Democratic politicians Bernie Sanders, Elizabeth Warren, and Joe Biden (ratings of Democrats; $\alpha=0.753 ; 31.84 \%$ of explained variance, eigen value $=1.911)$.

Table 9 Factor loadings for factor analysis with varimax rotation of the favorableness ratings of the six politicians in study 3

\begin{tabular}{lll}
\hline Variable & 1 & 2 \\
\hline Mike Pence & .907 & .031 \\
Donald Trump & .880 & -.133 \\
Mitt Romney & .729 & .317 \\
Bernie Sanders & -.251 & .788 \\
Elizabeth Warren & .116 & .857 \\
Joe Biden & .279 & .790 \\
\hline
\end{tabular}

\section{Appendix B: Self-generated materials of the three studies}

\section{Items assessing the attitude towards the use of desirable difficulties at school}

These items were assessed on a scale from 1 (totally disagree) to 7 (totally agree).

1. In school students should acquire knowledge themselves.

2. Students remember things better if they deduced the solution themselves.

3. In school there should be simulated test situations to check the students learning progress and knowledge gaps.

4. Several topics should be shuffled and spread across the lessons.

5. In school students should be given materials and exercise opportunities to prepare for the exams on their own. 


\section{Items assessing the attitude towards the difficulty of the learning process}

1. Learning at school should be ... $(1=$ Easy $-7=$ Hard $)$

2. Learning at school should be ... $(1=$ Not challenging at all $-7=$ Extremely challenging)

3. Learning at school should be $\ldots(1=$ Not exhausting at All $-7=$ Extremely exhausting)

\section{Acknowledgements None}

Funding Open Access funding enabled and organized by Projekt DEAL. This research was supported by a LOEWE grant from the Hessian Ministry for Science and the Arts entitled "desirable difficulties; intrinsic cognitive motivation and performance expectancies" awarded to Marc-André Reinhard.

\section{Declarations}

Conflict of interest The authors declare that they have no conflict of interest.

Availability of data and materials The data and the materials underlying these studies are available from the corresponding author upon request.

Ethical approval and consent to participate These studies were conducted in accordance with the Ethical Guidelines of the German Association of Psychologists (DGPs) as well as the American Psychological Association (APA), and the project was approved by the Ethics Committee affiliated with the funding source. Additionally, by the time the data were acquired it was neither customary at Kassel University nor at most other German universities to seek ethics approval for simple studies on personality and attitudes. Thus, ethical approval was not required for this study in accordance with the national and institutional guidelines. However, the studies exclusively make use of anonymous questionnaires and no identifying information were obtained from participants. Moreover, every participant had to read and agree to two questions concerning their consent. They were also explicitly informed that all their data would be treated confidentially and that they could withdraw from the study at any given time, without explanation, by simply closing the internet browser.

Open Access This article is licensed under a Creative Commons Attribution 4.0 International License, which permits use, sharing, adaptation, distribution and reproduction in any medium or format, as long as you give appropriate credit to the original author(s) and the source, provide a link to the Creative Commons licence, and indicate if changes were made. The images or other third party material in this article are included in the article's Creative Commons licence, unless indicated otherwise in a credit line to the material. If material is not included in the article's Creative Commons licence and your intended use is not permitted by statutory regulation or exceeds the permitted use, you will need to obtain permission directly from the copyright holder. To view a copy of this licence, visit http://creativecommons.org/licenses/by/4.0/.

\section{References}

Adorno, T. W., Frenkel-Brunswik, E., Levinson, D. J., \& Sanford, R. N. (1950). The authoritarian personality. Verso Books.

Ajzen, I. (1991). The theory of planned behavior. Organizational Behavior and Human Decision Processes, 50(2), 179-211. https://doi.org/10.1016/0749-5978(91)90020-T 
Bakker, A. B., Demerouti, E., \& Lieke, L. (2012). Work engagement, performance, and active learning: The role of conscientiousness. Journal of Vocational Behavior, 80(2), 555-564. https://doi.org/10. 1016/j.jvb.2011.08.008

Bertsch, S., Pesta, B. J., Wiscott, R., \& McDaniel, M. A. (2007). The generation effect: A meta-analytic review. Memory \& Cognition, 35(2), 201-210. https://doi.org/10.3758/BF03193441

Bjork, E. L., \& Bjork, R. A. (2011). Making things hard on yourself, but in a good way: Creating Desirable Difficulties to Enhance Learning. In M. A. Gernsbacher, R. W. Pew, L. M. Hough, \& J. R. Pomerantz (Eds.), Psychology and the Real World (pp. 56-64). Worth.

Bjork, E. L., Soderstrom, N. C., \& Little, J. L. (2015). Can multiple-choice testing induce desirable difficulties? Evidence from the laboratory and the classroom. The American Journal of Psychology, 128(2), 229-239. https://doi.org/10.5406/amerjpsyc.128.2.0229

Bjork, R. A. (1994). Memory and metamemory considerations in the training of human beings. In J. Metcalfe \& A. Shimamura (Eds.), Metacognition: Knowing about Knowing (pp. 185-205). MIT Press.

Bjork, R.A., \& Bjork, E.L. (1992). A new theory of disuse and an old theory of stimulus fluctuation. In A. Healy, S. Kosslyn, \& R. Shiffrin (Eds.), From learning processes to cognitive processes: Essays in honor of William K. Estes (Vol. 2, pp. 35-67). Erlbaum.

Bjork, R. A., \& Bjork, E. L. (2019). Forgetting as the friend of learning: Implications for teaching and self-regulated learning. Advances in Physiology Education, 43(2), 164-167. https://doi.org/10.1152/ advan.00001.2019

Bjork, R. A., \& Kroll, J. F. (2015). Desirable difficulties in vocabulary learning. The American Journal of Psychology, 128(2), 241-252. https://doi.org/10.5406/amerjpsyc.128.2.0241

Blais, A., \& St-Vincent, S. L. (2011). Personality traits, political attitudes and the propensity to vote. European Journal of Political Research, 50(3), 395-417. https://doi.org/10.1111/j.1475-6765.2010. 01935.x

Bleakley, A., Hennessy, M., \& Fishbein, M. (2010). Predicting preferences for types of sex education in US schools. Sexuality Research and Social Policy, 7(1), 50-57. https://doi.org/10.1007/ s13178-010-0008-Z

Bligh, M. C., Schlehofer, M. M., Casad, B. J., \& Gaffney, A. M. (2012). Competent enough, but would you vote for her? Gender stereotypes and media influences on perceptions of women politicians. Journal of Applied Social Psychology, 42(3), 560-597. https://doi.org/10.1111/j.1559-1816.2011. 00781.x

Book, C., Byers, J., \& Freeman, D. (1983). Student expectations and teacher education traditions with which we can and cannot live. Journal of Teacher Education, 34(1), 9-13. https://doi.org/10.1177/ 002248718303400103

Budesheim, T. L., \& DePaola, S. J. (1994). Beauty or the beast? The effects of appearance, personality, and issue information on evaluations of political candidates. Personality and Social Psychology Bulletin, 20(4), 339-348. https://doi.org/10.1177/0146167294204001

Buhrmester, M., Kwang, T., \& Gosling, S. D. (2011). Amazon's mechanical turk: A new source of inexpensive, yet high-quality data? Perspectives on Psychological Science, 6(1), 3-5. https://doi.org/10. $1177 / 1745691610393980$

Busemeyer, M. R., Cattaneo, M. A., \& Wolter, S. C. (2011). Individual policy preferences for vocational versus academic education: Microlevel evidence for the case of Switzerland. Journal of European Social Policy, 21(3), 253-273. https://doi.org/10.1177/0958928711401769

Busemeyer, M. R., \& Trampusch, C. (2011). Review article: comparative political science and the study of education. British Journal of Political Science, 41(2), 413-443. https://doi.org/10.1017/ S0007123410000517

Carney, D. R., Jost, J. T., Gosling, S. D., \& Potter, J. (2008). The secret lives of liberals and conservatives: Personality profiles, interaction styles, and the things they leave behind. Political Psychology, 29(6), 807-840. https://doi.org/10.1111/j.1467-9221.2008.00668.x

Cisłak, A., \& Wojciszke, B. (2006). The role of self-interest and competence in attitudes towards politicians. Polish Psychological Bulletin, 37(4), 203-212.

Condra, M. B. (1992). The link between need for cognition and political interest, involvement, and media usage. Phychology A Journal of Human Behavior, 29(3-4), 13-18.

Conservative vs. Liberal Beliefs. (2010). Retrieved from https://www.studentnewsdaily.com/conse rvative-vs-liberal-beliefs/

Craik, F. I., \& Tulving, E. (1975). Depth of processing and the retention of words in episodic memory. Journal of Experimental Psychology: General, 104(3), 268-294. https://doi.org/10.1037/00963445.104.3.268 
Democratic Platform Committee (2016). 2016 Democratic Party Platform. Retrieved October 30, 2019, from https://prod-static-ngop-pbl.s3.amazonaws.com/media/documents/DRAFT_12_ FINAL\%5B1\%5D-ben_1468872234.pdf

Diemand-Yauman, C., Oppenheimer, D. M., \& Vaughan, E. B. (2010). Fortune favors the bold (and the italicized): Effects of disfluency on educational outcomes. Cognition, 118(1), 111-115. https://doi.org/10.1016/j.cognition.2010.09.012

Dobson, J. L., \& Linderholm, T. (2015). The effect of selected "desirable difficulties" on the ability to recall anatomy information. Anatomical Sciences Education, 8(5), 395-403. https://doi.org/10. 1002/ase.1489

Eilam, B., Zeidner, M., \& Aharon, I. (2009). Student conscientiousness, self-regulated learning, and science achievement: An explorative field study. Psychology in the Schools, 46(5), 420-432. https://doi.org/10.1002/pits.20387

Faul, F., Erdfelder, E., Buchner, A., \& Lang, A. G. (2009). Statistical power analyses using G* Power 3.1: Tests for correlation and regression analyses. Behavior Research Methods, 41(4), 11491160. https://doi.org/10.3758/BRM.41.4.1149

Frimer, J. A., \& Skitka, L. J. (2018). The Montagu Principle: Incivility decreases politicians' public approval, even with their political base. Journal of Personality and Social Psychology, 115(5), 845. https://doi.org/10.1037/pspi0000140

Garritzmann, J. L. (2015). Attitudes towards student support: How positive feedback-effects prevent change in the Four Worlds of Student Finance. Journal of European Social Policy, 25(2), 139158. https://doi.org/10.1177/0958928715573478

Garritzmann, J. L., \& Seng, K. (2016). Party politics and education spending: Challenging some common wisdom. Journal of European Public Policy, 23(4), 510-530. https://doi.org/10.1080/13501 763.2015.1048703

Garzia, D. (2011). The personalization of politics in Western democracies: Causes and consequences on leader-follower relationships. The Leadership Quarterly, 22(4), 697-709. https://doi.org/10. 1016/j.leaqua.2011.05.010

Gerring, J. (2001). Party ideologies in America, 1828-1996. Cambridge University Press.

Hallermann, A., \& Kaim, M. (2003). Parteien im internationalen Vergleich. Landeszentrale für Politische Bildung Thüringen.

The Harris Poll. (2017). Monthly Harvard-Harris Poll: April 2017. Retrieved from http://harvardhar rispoll.com/wp-content/uploads/2017/04/Harvard-CAPS-Harris-Poll-April-Wave-Topline-Favor ability-04.18.2017.pdf

The Harris Poll. (2019). Monthly Harvard-Harris Poll: October 2019. Retrieved from https://harva rdharrispoll.com/wp-content/uploads/2019/11/HHP_October19_Topline_RegisteredVoters.pdf

Hauser, D. J., \& Schwarz, N. (2016). Attentive Turkers: MTurk participants perform better on online attention checks than do subject pool participants. Behavior Research Methods, 48(1), 400-407. https://doi.org/10.3758/s13428-015-0578-z

Heflick, N. A., \& Goldenberg, J. L. (2011). Sarah Palin, a nation object (ifie) s: The role of appearance focus in the 2008 US presidential election. Sex Roles, 65(3-4), 149-155. https://doi.org/10. 1007/s11199-010-9901-4

Hinze, T., Doster, J., \& Joe, V. C. (1997). The relationship of conservatism and cognitive-complexity. Personality and Individual Differences, 22(2), 297-298. https://doi.org/10.1016/S0191-8869(96)00171-7

Jost, J. T., Glaser, J., Kruglanski, A. W., \& Sulloway, F. (2003a). Exceptions that prove the rule: Using a theory of motivated social cognition to account for ideological incongruities and political anomalies. Psychological Bulletin, 129(3), 383-393. https://doi.org/10.1037/0033-2909.129.3.383

Jost, J. T., Glaser, J., Kruglanski, A. W., \& Sulloway, F. (2003b). Political conservatism as motivated social cognition. Psychological Bulletin, 129(2), 339-375. https://doi.org/10.1037/0033-2909.129.3.339

Jungblut, J. (2016). Party Politics in Higher Education Policy. Partisan Preferences, Coalition Positions and Higher Education Policy in Western Europe [Doctoral dissertation, University of Oslo].

Karpicke, J. D., Butler, A. C., Roediger, H. L., \& III. (2009). Metacognitive strategies in student learning: Do students practise retrieval when they study on their own? Memory, 17(4), 471-479. https://doi. org/10.1080/09658210802647009

Koriat, A., \& Ma'ayan, H. (2005). The effects of encoding fluency and retrieval fluency on judgments of learning. Journal of Memory and Language, 52(4), 478-492. https://doi.org/10.1016/j.jml.2005.01. 001 
Krieger, F., Becker, N., Greiff, S., \& Spinath, F. M. (2019). Big-Five personality and political orientation: Results from four panel studies with representative German samples. Journal of Research in Personality, 80, 78-83. https://doi.org/10.1016/j.jrp.2019.04.012

McDaniel, M. A., \& Butler, A. C. (2011). A contextual framework for understanding when difficulties are desirable. Successful Remembering and Successful Forgetting: A Festschrift in Honor of Robert a. Bjork, 1, 175-198.

Minton, E., Gurel-Atay, E., Kahle, L., \& Ring, K. (2013). Comparing data collection alternatives: Amazon Mturk, college students, and secondary data analysis. In AMA Winter Educators' Conference Proceedings (Vol. 24, pp. 36-37).

Norris, P. (2003). Young People \& Political Activism: From the Politics of Loyalties to the Politics of Choice? Report presented at the Council of Europe Symposium ("Young people and democratic institutions: from disillusionment to participation”). November 27-28, Strasbourg.

Pfattheicher, S., \& Schindler, S. (2016). Misperceiving bullshit as profound is associated with favorable views of Cruz, Rubio Trump and Conservatism. PLoS ONE, 11(4), e0153419. https://doi.org/10. 1371/journal.pone.0153419

Pyc, M. A., \& Rawson, K. A. (2009). Testing the retrieval effort hypothesis: Does greater difficulty correctly recalling information lead to higher levels of memory? Journal of Memory and Language, 60(4), 437-447. https://doi.org/10.1016/j.jml.2009.01.004

Ranking Committee. (2019). So if Trump gets removed, who's the GOP nominee? Retrieved from https:// www.washingtonpost.com/opinions/2019/10/11/so-if-trump-gets-impeached-whos-gop-nominee/? arc404=true.Van\%20Hiel,\%20A.,\%20Pandelaere,\%20M.,\%20\&\%20Duriez,\%20B.\%20(2004).\% 20The $\% 20$ impact $\% 20$ of $\% 20$ need $\% 20$ for $\% 20$ closure $\% 20$ on $\% 20$ conservative $\% 20$ beliefs $\% 20$ and $\%$ 20racism:\%20Differential\%20mediation \%20by\%20authoritarian\%20submission $\% 20$ and $\% 20$ authorit arian\%20dominance.

Republican National Committee (2016). Republican Platform 2016. Retrieved from https://prod-staticngop-pbl.s3.amazonaws.com/media/documents/DRAFT_12_FINAL\%5B1\%5D-ben_1468872234. pdf

Roediger, H. L., \& Karpicke, J. D. (2006). The power of testing memory: Basic research and implications for educational practice. Perspectives on Psychological Science, 1(3), 181-210. https://doi.org/10. 1111/j.1745-6916.2006.00012.x

Schoen, H., \& Schumann, S. (2007). Personality traits, partisan attitudes, and voting behaviour Evidence from Germany. Political Psychology, 28(4), 471-498. https://doi.org/10.1111/j.1467-9221.2007. 00582.x

Sibley, C. G., Osborne, D., \& Duckitt, J. (2012). Personality and political orientation: Meta-analysis and test of a threat-constraint model. Journal of Research in Personality, 46(6), 664-677. https://doi.org/ 10.1016/j.jrp.2012.08.002

Soldz, S., \& Vaillant, G. E. (1999). The Big Five personality traits and the life course: A 45-year longitudinal study. Journal of Research in Personality, 33(2), 208-232. https://doi.org/10.1006/jrpe.1999. 2243

Thomas, R. M. (Ed.). (2016). Politics and education: Cases from eleven nations. NewYork: Elsevier.

Tyler, S. W., Hertel, P. T., McCallum, M. C., \& Ellis, H. C. (1979). Cognitive effort and memory. Journal of Experimental Psychology: Human Learning and Memory, 5(6), 607-617. https://doi.org/10. 1037/0278-7393.5.6.607

Vecchione, M., Schoen, H., Castro, J. L. G., Cieciuch, J., Pavlopoulos, V., \& Caprara, G. V. (2011). Personality correlates of party preference: The big five in five big European countries. Personality and Individual Differences, 51(6), 737-742. https://doi.org/10.1016/j.paid.2011.06.015

Verhulst, B., Lodge, M., \& Lavine, H. (2010). The attractiveness halo: Why some candidates are perceived more favorably than others. Journal of Nonverbal Behavior, 34(2), 111-117. https://doi.org/ 10.1007/s10919-009-0084-z

Vermunt, J. D. (1994). Inventory of learning styles in higher education: Scoring key for the inventory of learning styles in higher education. Tilburg University, Department of Educational Psychology.

Weissgerber, S. C., \& Reinhard, M. A. (2017). Is disfluency desirable for learning? Learning and Instruction, 49, 199-217. https://doi.org/10.1016/j.learninstruc.2017.02.004

Weissgerber, S. C., Reinhard, M. A., \& Schindler, S. (2016). Study harder? The relationship of achievement goals to attitudes and self-reported use of desirable difficulties in self-regulated learning. Journal of Psychological and Educational Research, 24(1), 42-60. 
Weissgerber, S. C., Reinhard, M. A., \& Schindler, S. (2018). Learning the hard way: Need for cognition influences attitudes toward and self-reported use of desirable difficulties. Educational Psychology, 38(2), 176-202. https://doi.org/10.1080/01443410.2017.1387644

Wiborg, S. (2015). Privatizing education: Free school policy in Sweden and England. Comparative Education Review, 59(3), 473-497. https://doi.org/10.1086/681928

Yan, V. X., Clark, C. M., \& Bjork, R. A. (2016). Memory and metamemory considerations in the instruction of human beings revisited: Implications for optimizing online learning. In J. C. Horvath, J. Lodge, \& J. A. C. Hattie (Eds.), From the laboratory to the classroom: Translating the learning sciences for teachers (pp. 61-78). Routledge.

Publisher's Note Springer Nature remains neutral with regard to jurisdictional claims in published maps and institutional affiliations.

Antonia Mariss is a Master student of Psychology at the University of Kassel where she worked as a student assistant for the Social Psychology at the Department of Psychology. She thereby focused, among others, on attitudes towards desirable difficulties and difficult learning strategies. Other research interests include the belief in a just world.

Kristin Wenzel is a $\mathrm{PhD}$ student and research assistant at the Department of Psychology, University of Kassel, Germany. Her research interests include cognitive prerequisites and moderators of the positive effect of desirable difficulties as well as (negative) consequences of desirable difficulties. Additionally, her research focuses on deception and deception detection as well as on the belief in a just world.

Chawwah Grünberg recently completed her Master's degree in Clinical Psychology and Psychotherapy at the University of Kassel. She works as a psychologist in a social psychiatric practice with children and adolescents and teaches university courses on systemic therapy. Her research interests include ruptures in the psychotherapeutic alliance, the intertwining of body and mind, as well as systemic and constructivist worldviews and mindsets in psychotherapy and psychological diagnosis.

Marc-André Reinhard is a Full Professor of Social Psychology at the Department of Psychology, University of Kassel, Germany. His research interests include cognitive and motivational moderators of the positive effect of desirable difficulties in learning as well as the formation and consequences of performance expectancies. Moreover, his research focuses on deception detection and on the occurrence of deception in different contexts.

\section{Authors and Affiliations}

\section{Antonia Mariss $^{1}\left[\right.$ - Kristin Wenzel ${ }^{1}\left[{ }^{10} \cdot\right.$ Chawwah Grünberg $^{1}$. Marc-André Reinhard'}

Antonia Mariss

antonia.mariss@student.uni-kassel.de

$\bowtie$ Kristin Wenzel

kristin.wenzel@uni-kassel.de

Chawwah Grünberg

chawwahgruenberg@posteo.de

Marc-André Reinhard

reinhard@psychologie.uni-kassel.de

1 Department of Psychology, University of Kassel, Holländische Straße 36-38, 34127 Kassel, Germany 